\title{
PRESENCIA DE LA PEDAGOGÍA EN EL ACTO DE CAMINAR: HOMO VIATTOR, NOMADISMO Y FORMACIÓN
}

\section{PRESENCE OF PEDAGOGY IN THE ACT OF WALKING: HOMO VIATTOR, NOMADISM AND TRAINING}

\author{
Jordi GARCÍA FARRERO \\ Universidad de Barcelona \\ jgarciaf@ub.edu
}

\section{Resumen:}

El presente artículo pretende explorar la posibilidad de pensar la pedagogía desde el acto de caminar a partir de una visión interdisciplinar (filosofía; literatura; historia y filosofía de la educación). Para ello, el autor realiza un ejercicio que contempla tres tipos de entradas: la primera de ellas pone de manifiesto la figura del Homo viātor (el hombre que camina) mediante la tradición cosmovisional (Jaspers, Dilthey) y la pedagogía de las ciencias del espíritu (Spranger, Bollnow); luego, estudia la relación que se establece entre el conocimiento y el nomadismo a partir de las experiencias pedestres de Rousseau, Goethe y Nietzsche; por último, presenta una serie de prácticas pedestres autoformativas y heteroeducativas que confirman la conexión entre este método educativo y diferentes tradiciones pedagógicas (naturalismo, culturalismo y postestructuralismo). Se trata, pues, de un estudio que se ha llevado a cabo a través de la hermenéutica de diferentes textos y autores.

Palabras clave: Caminar; Rousseau; Goethe; Nietzsche; Homo viātor; Nomadismo; Formación.

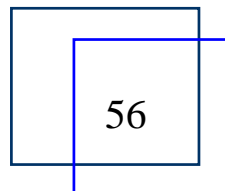




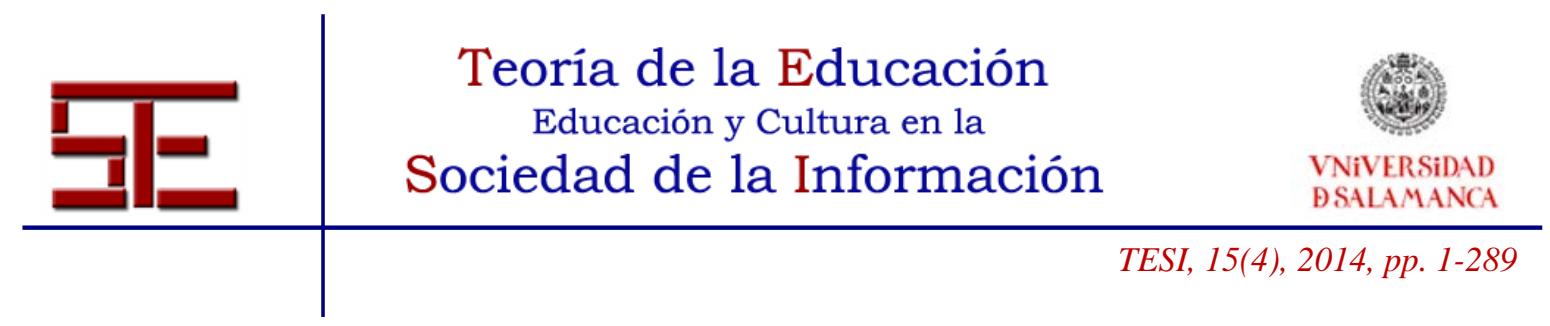

\begin{abstract}
This paper aims to explore the possibility of thinking about pedagogy through the act of walking from an interdisciplinary approach (philosophy, literature, history of education, philosophy of education). To do this, I carry out an exercise that involves three types of inputs: the first shows the figure of Homo Viator (man walking) through a traditional world-view (Jaspers, Dilthey) and the pedagogy of the human sciences (Spranger, Bollnow); later on, I study the relationship established between knowledge and nomadism from pedestrian experiences (Rousseau, Goethe, and Nietzsche); finally, I present a series of self-training and pedestrian practices of heteroeducation confirming the connection between this educational method and different pedagogical traditions (naturalism, culturalism and post-structuralism). This analysis has been carried out through the hermeneutics of different texts and authors.
\end{abstract}

Key words: Walk; Rousseau; Goethe; Nietzsche; Homo Viator; Nomadism; Education.

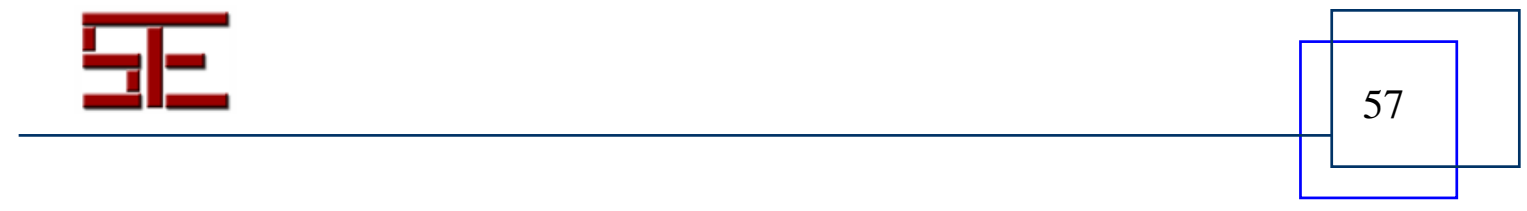




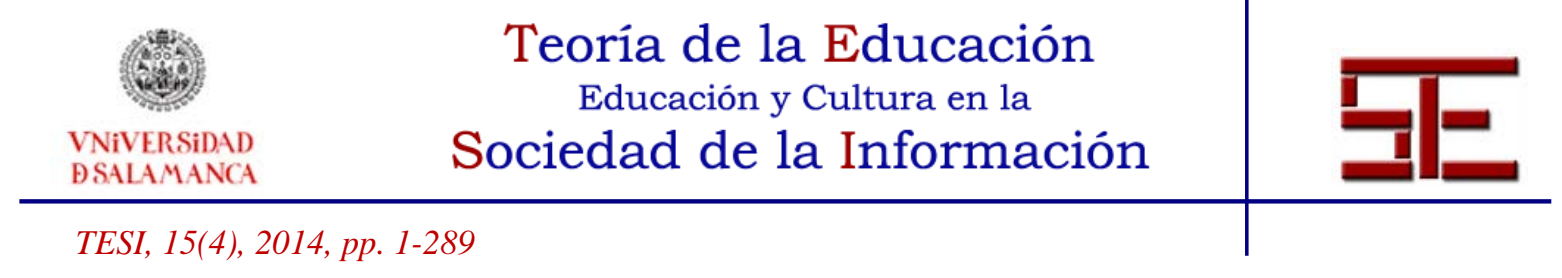

\section{INTRODUCCIÓN}

No hay duda de que la palabra caminar -proveniente del término camino que es de origen céltico (Coromines, 1980) ${ }^{1}$ - hace referencia, básicamente, a una "acción que sirve para trasladarse de un lugar a otro" (Real Academia Española, 2001, 413). Por ello, somos conscientes de que escribir un artículo teórico-educativo puede parecer, en principio, una tarea muy simple y provocada por un afán de sofistería. Sin embargo, la historia de diferentes disciplinas científicas nos muestra que es posible liberar dicha palabra de su aparente evidencia y trivialidad para convertirla en un objeto de estudio claramente complejo, nada lineal y con diferentes teorías que a menudo se contradicen. Es bien sabido que existe bastante literatura sobre la hominización vista desde la locomoción bípeda (antropología física), la evolución física y motora (psicología del desarrollo) o el análisis de la marcha normal y patológica (ciencias de la salud).

De igual modo, podemos decir que este artículo pretende llevar a cabo una lectura pedagógica del acto de caminar con la intención de explorar la posibilidad de una educación pedestre a partir de tres experiencias acaecidas durante la modernidad de los siglos XVIII y XIX y, al mismo tiempo, protagonizadas por tres grandes pensadores occidentales: los paseos rousseaunianos, el viaje cultural goethiano y las caminatas nietzscheanas. Al hilo de lo que estamos diciendo, empezamos enunciando cinco apuntes que fijen nuestra posición en relación a la acción de ir a pie más allá de la definición emitida por el diccionario de la lengua porque consideramos que será fundamental para toda reflexión ulterior.

1. Caminar tiene múltiples significados, tantos como sinónimos (andar, marchar, deambular, viajar, transitar o pasear). Por lo tanto: existen muchas formas de caminar un mismo recorrido.

2. El acto de caminar se puede interpretar como una Koiné universal de todos los seres humanos, ya que nos permite tener más información sobre el carácter de una persona y, valga la redundancia, conocer de qué pie cojea. No hay duda de que el ritmo (lento, rápido), la postura (altiva, reposada), la apariencia (forma de vestir, tipo de calzado) y el tipo de paso son aspectos muy reveladores en este sentido.

\footnotetext{
${ }^{1}$ Su forma temprana es la de cammīnus (céimm del irlandés y cam del galés) y fue extraña al latín arcaico y clásico, pero no podemos decir lo mismo en cuanto a su penetración en el latín vulgar. Prueba elocuente de ello es su descendencia en todas las lenguas románicas salvo el rumano (plimbáre): caminar (catalán), caminhar (portugués), cheminer (francés), camminare (italiano) y camiñar (gallego). Otro dato muy significativo es que camminnus, cuya aparición se documenta por primera vez en España en el siglo VII, se convirtió en sinónimo de calle (del latín callis). Por lo cual, cabe recordar que el lugar por donde se camina condiciona a sus principales derivados (caminar y caminante) y, por este motivo, tiene una gran diversidad de formas que se manifiesta en la riqueza del lenguaje popular para denominarlos. Como ejemplo destacamos algunos de ellos: senderos, trillados, de ronda o de cabras, senda, vereda, pista, cañada o trocha.
}

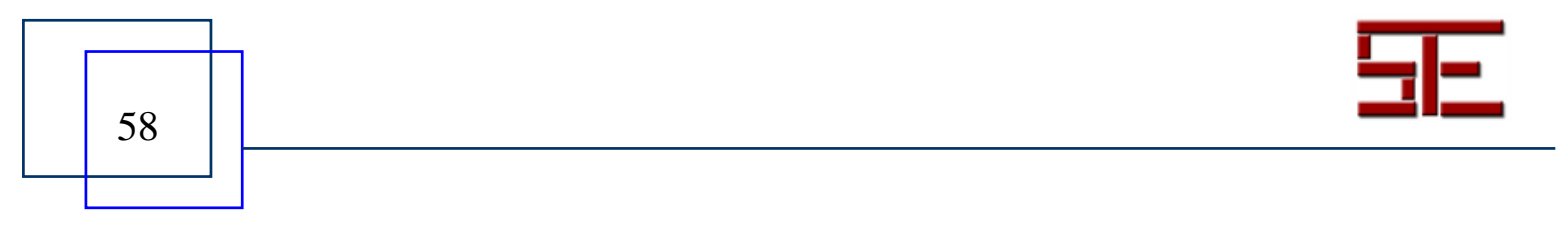




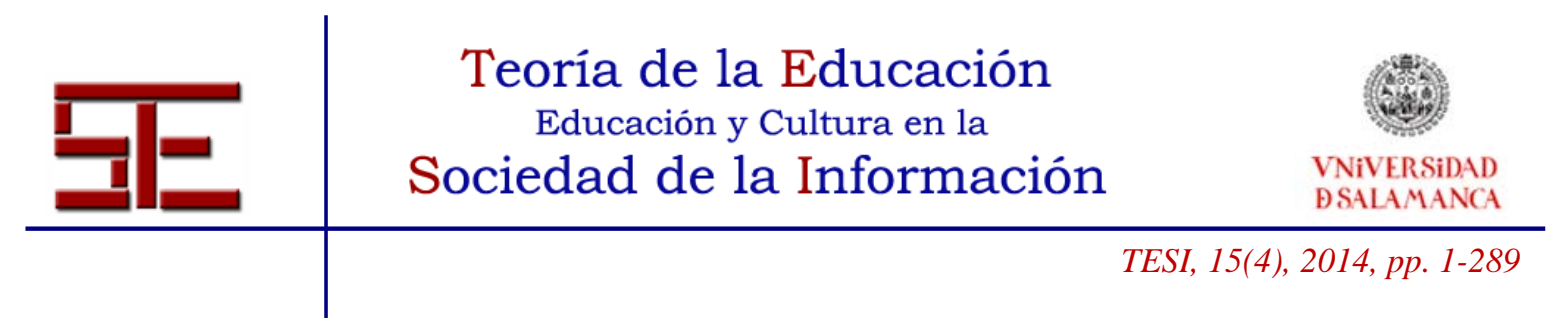

3. Caminar nos recuerda que nuestro pie no tiene raíces y está hecho para que nos podamos mover para reducir la inmensidad del mundo a las proporciones de nuestro cuerpo.

4. Caminar nos permite construir nuestro tiempo ya que podemos acelerar o aflojar el paso en función de nuestros deseos y, además, nuestro tiempo a partir de lo que observamos.

5. Caminar es una experiencia genuinamente humana que reconcilia la vida contemplativa y la de acción porque da pie a la interpelación; al pensamiento; a la conversación; al disfrute del tiempo y del aire libre; al aprendizaje de lo que se observa; a la comprensión del otro; al diálogo con textos y autores; a la liberación del peso de las obligaciones y de las preocupaciones.

Por consiguiente: la palabra caminar puede tener una sonoridad simple pero su aspecto es poliédrico porque es algo más que desplazarse de un lugar a otro o una habilidad adquirida que nos acompaña toda la vida dado que puede suscitar otras experiencias de primer orden (inspiraciones literarias, espiritualidad, vivencias estéticas, comprobaciones científicas, descubrimientos artísticos reveladores, autoconocimiento, desobediencia civil y otras). En cualquier caso, queremos poner de manifiesto desde ahora mismo que esta actividad no puede ser percibida como una menudencia porque, en la mayoría de las ocasiones, significa una lección natural, tangible y real para el propio caminante tal y como ya han puesto de manifiesto profesores de la talla de Le Breton (2000), Careri (2002), Demetrio (2005), Delgado (2007) y Gros (2009) desde la filosofía, la antropología o la historia del arte.

\section{LA FIGURA DEL HOMO VIATOR}

Weltanschauung -palabra alemana formada por Welt (mundo) y Anschauung (visión o concepción)- se puede traducir por cosmovisión. De modo que las cosmovisiones constituyen imágenes de la totalidad del mundo y, por consiguiente, podemos decir que la idea de la imagen del mundo ha venido a substituir, en parte, a la metafísica basada en la ontología del ser, para recordarnos la temporalidad del ser.

En cualquier caso, la tradición cosmovisional responde a grandes concepciones antropológicas que generan otras tan importantes como son las psicológicas o pedagógicas. En cuanto la primera perspectiva, sostenemos que es importante citar la obra Psicología de las concepciones del mundo de Karl Jaspers porque explica que es a partir de una de las tres actitudes existentes (la objetiva, la autorreflexiva y el entusiasta) que cada individuo elabora su propia Weltanschauung.

En cuanto a la pedagógica, encontramos autores tan importantes como Wilhelm Dilthey, que intentó ordenar la pluralidad de concepciones del mundo por medio de una teoría

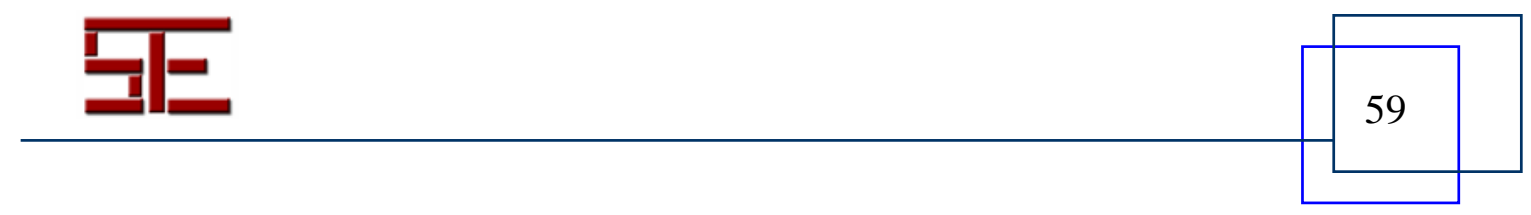




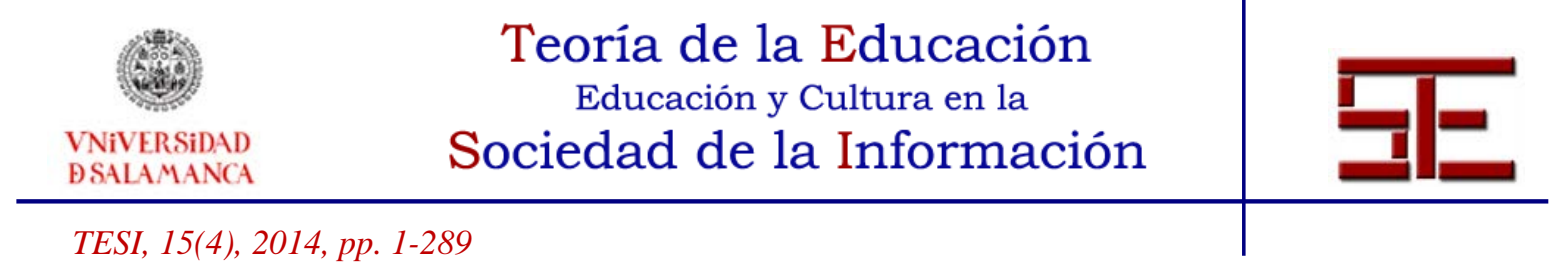

con base histórica (el naturalismo de base empirista y proyección materialista, el idealismo de la libertad y la idealismo objetivo) en Teoría de las concepciones del mundo y, por supuesto, uno de sus discípulos, Eduard Spranger, ya que en uno de sus libros -Formas de vida. Psicología y ética de la personalidad- este filósofo, psicólogo y pedagogo alemán indica que cada tipo de estructura psicológica-espiritual individual

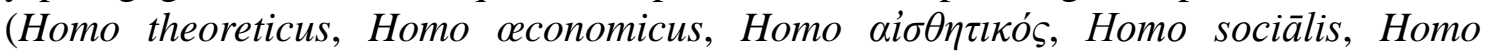
politǐcus y Homo religiōsus) está relacionada con una cosmovisión.

Ahora bien, es evidente que este artículo tiene la voluntad de completar el esquema de Spranger con la figura del Homo viätor porque consideramos que representa claramente una particular visión del mundo, es decir, una manera de estar en el mundo que tiene el anhelo de huir de la inmovilidad para disfrutar del aire libre y posibilitar que el desplazamiento se convierta en una experiencia de primer orden. En este sentido, también se pronunció Otto Bollnow en el libro Hombre y espacio diciendo que el acto de caminar significa una antítesis entre las cuestiones delante y detrás. O sea: "delante es lo que se extiende ante nosotros en el futuro como un tramo de vida por recorrer aún; detrás es el trecho recorrido del camino de la vida, el pasado" (Bollnow, 1969, 56). Y no sólo eso: percibe un Homo viätor como un Wandern porque su actividad no tiene ninguna pretensión de llegar lo antes posible a su destino y, al mismo tiempo, quiere huir de su mundo cotidiano para liberarse de los esfuerzos y preocupaciones diarias. Por consiguiente, resulta evidente que dicho sujeto nos da la posibilidad de visibilizar el acto de caminar como una acción más completa que la que expresa el diccionario general de la lengua.

A modo de contrapunto, finalizamos este epígrafe dejando constancia que la tradición filosófica cristiana también ha planteado contribuciones bien significativas en torno la figura del Homo viātor como uno de los posibles organizadores de la vida espiritual. En este sentido, Gabriel Marcel sostiene que el acto de caminar es una manera de vivir y de filosofar totalmente adecuada porque ayuda a cuestionarse los problemas vitales más fundamentales y a dialogar con grandes autores. Buena prueba de ello es una de sus obras que precisamente lleva por título Homo viātor porque, desde esta perspectiva, reflexiona sobre la esperanza, la familia, la inmortalidad, los valores, la salvación, la dimensión espiritual y otros asuntos. En la misma sintonía, hallamos otra referencia en el libro Las virtudes fundamentales de Josep Pieper que destaca que en la teología existen dos conceptos antagónicos: el status viatoris (el sujeto que está en camino) y el status comprehensoris (el sujeto que ya lo ha captado). En cuanto la noción que nos interesa, este pensador alemán pone de manifiesto que tienen un aspecto negativo (falta de plenitud) y otro positivo (encaminamiento hacia la plenitud). Por ello, concluye que el ser humano siempre está buscando una respuesta -solamente existe, según su juicio, la de la esperanza porque es la única que entiende el hombre como criatura de Dios que es- para no caer en el abismo que representa el nihilismo.

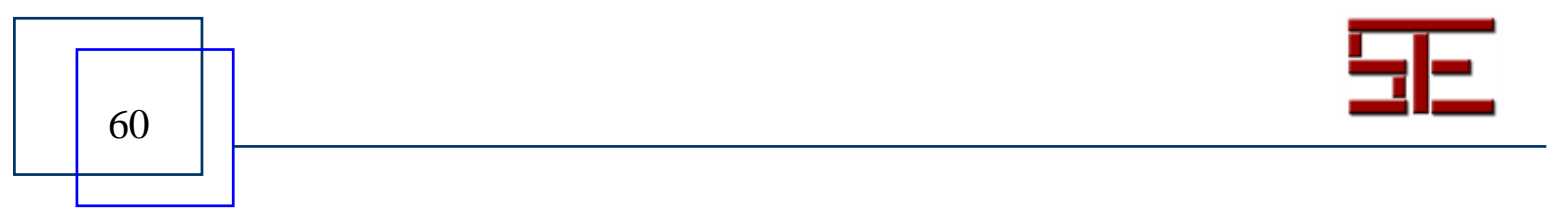




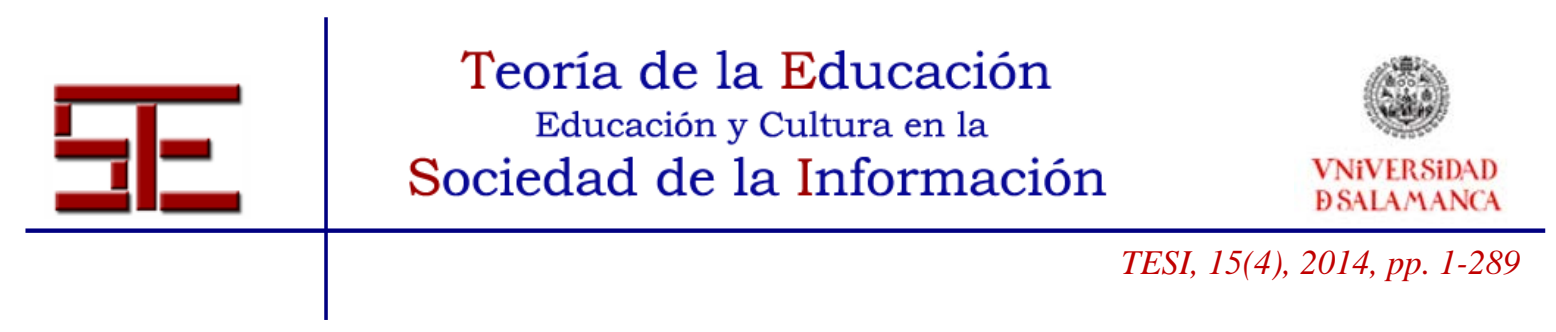

\section{CAMINAR Y EXPERIENCIA: A PROPÓSITO DE ROUSSEAU, GOETHE Y NIETZSCHE}

Con el acto de caminar en el centro de gravedad de nuestra reflexión pedagógica, anunciamos que en este apartado abordaremos la experiencia más significativa relacionada con nuestro objeto de estudio de tres autores que han sido escogidos conscientemente porque son claros referentes del pensamiento europeo. Sin la intención de querer agotar el tema, ahora queremos apostillar el asunto de la experiencia estableciendo un diálogo con el pensador alemán Hans-Georg Gadamer (2012) a partir de un texto tan interesante y sugestivo como es el caso de El concepto de la experiencia y la esencia de la experiencia hermenéutica.

En las primeras páginas de este estudio, el filósofo de Heidelberg fija su posición con relación a la situación en la que se encuentra el concepto en cuestión. Dice que es uno de los temas menos aclarados a lo largo de la historia del pensamiento occidental y, a su parecer, esto ha venido motivado porque las ciencias naturales lo han sometido a una esquematización epistemológica. Es decir: la mayoría de las veces ha sido abordado sin cuidar de su historicidad interna, porque su finalidad ha sido más bien objetivar la experiencia a través de su organización metodológica.

Después de mencionar estas dos ideas previas fundamentales, la misión de Gadamer pasa a ser la de buscar la estructura verdadera de la experiencia hermenéutica. Conviene explicar que lleva a cabo este ejercicio de la siguiente forma: en primer lugar, dialoga con Aristóteles y Hegel y, finalmente, sintetiza en dos argumentos principales la respuesta sobre el significado que debe tener el concepto mencionado según su punto de vista.

He aquí, pues, la primera idea gadameriana: "la verdadera experiencia es siempre negativa” (Gadamer, 2012, 428). Resumiendo muy concisamente, podemos decir que esta cita pone de manifiesto que la experiencia consiste en un hecho inesperado que comporta el incumplimiento de muchas expectativas previas pero, al mismo tiempo, es sumamente productiva porque transforma el conjunto del saber del sujeto.

Sea como fuere, esta negatividad que representa la experiencia está muy presente en la trayectoria biográfica de los tres caminantes que abordaremos a continuación. Buena prueba es que todos ellos completaron sus itinerarios pedestres con una metamorfosis vital y, por supuesto, una modificación de la forma de conocimiento.

Otra cuestión que Gadamer plantea es el sujeto de la experiencia, el cual queda definido de este modo: "no es sólo alguien que se ha hecho el que es a través de experiencias, sino también alguien que está abierto a nuevas experiencias” (Gadamer, 2012, 431). Y, más adelante, añade: “es siempre el más radicalmente no dogmático, que precisamente porque ha hecho tantas experiencias y ha aprendido de tanta experiencia está particularmente capacitado para volver a hacer experiencias y aprender de ellas"

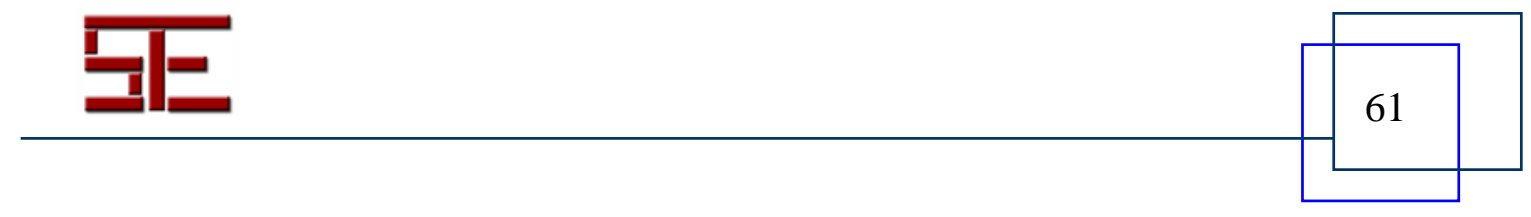




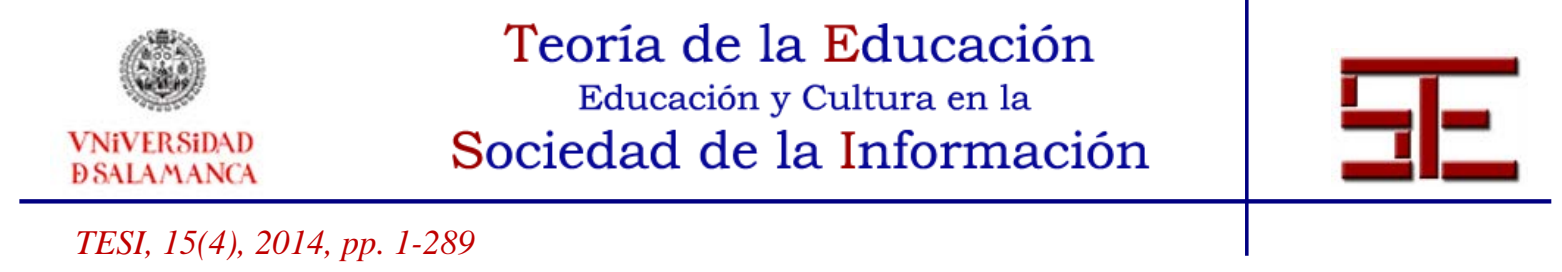

(Gadamer, 2012, 432).

De aquí viene que también consideremos a Rousseau, Goethe y Nietzsche en calidad de sujetos de la experiencia. Expliquémoslo: la dialéctica entre pensamiento y acción que propone el caminar solamente se puede entender desde una actitud abierta a la tradición $\mathrm{y}$, de este modo, dando pie a un diálogo sin fin con textos y autores, recuperando las eternas cuestiones que siempre nos interpelan y, para acabar, reavivando los mejores pensamientos. Por lo tanto: estar-en-camino no es otra cosa que un acontecimiento formativo con conciencia hermenéutica que nunca es susceptible de ser completado, siempre puede surgir una nueva experiencia.

\section{1.- Los paseos rousseaunianos (1762-1778): soledad, herborización y ensoñaciones}

Pues habiendo formado el proyecto de describir el estado habitual de mi alma en la posición más extraña en que mortal alguno podrá encontrarse nunca, no he visto manera más simple y más segura de ejecutar esta empresa que llevar un registro fiel de mis paseos solitarios y de las ensoñaciones que los llenan cuando dejo mi cabeza enteramente libre y a mis ideas seguir su inclinación sin resistencia ni traba. Esas horas de soledad y meditación son las únicas del día en que soy yo plenamente y para mí sin distracción ni obstáculo, y en que verdaderamente puedo decir que soy lo que la naturaleza ha querido (Rousseau, 2008, p. 33).

Observamos, pues, que en su última obra autobiográfica, Las ensoñaciones del paseante solitario (1782), es donde podemos percibir perfectamente la figura de este filósofo ginebrino en movimiento por la naturaleza y, sobre todo, el método que empleó durante aquellos años tal y como nos muestra la cita que abre este apartado. Aún así, no podemos olvidar que justo en aquella época nuestro autor era una persona atormentada por las disputas y las acusaciones realizadas por los enciclopedistas, motivo precisamente por el cual decidió huir del ambiente del París de la época ilustrada y dar pequeños paseos para rememorar su pasado y complacer su yo dolido y triste. Es decir: tenía el convencimiento de que los asuntos de Diderot y Voltaire habían motivado que empezara este ejercicio preguntándose “¿qué soy yo?” (Rousseau, 2008, 23).

Dicho esto, a continuación señalaremos una serie de particularidades que constituyen estos paseos rousseaunianos, puesto que no podemos olvidar que la principal finalidad de todas sus obras autobiográficas fue la de descubrir en su propia piel aquel tipo de hombre que no ha sido desfigurado por la cultura, la educación o las artes.

Para empezar, podemos destacar que solía caminar por senderos solitariamente. Aún así, cabe decir que la soledad rousseauniana, que en aquella época se convirtió en uno de sus principales ideales, vivió diferentes etapas en su vida, tal y como nos plantea Tzvetan Todorov. Nos estamos refiriendo, pues, a aquella soledad que quería recuperar la sociedad o la que desaprobaba totalmente todo lo social (Todorov, 1987). Por el contrario, fue cuando apareció una soledad feliz en la que percibió su situación como una oportunidad para dar vida y sentido al grabado del Templo de Delfos, gnosis

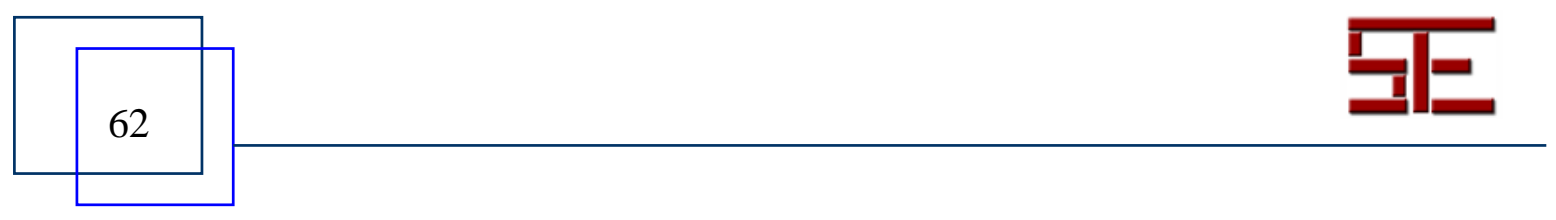




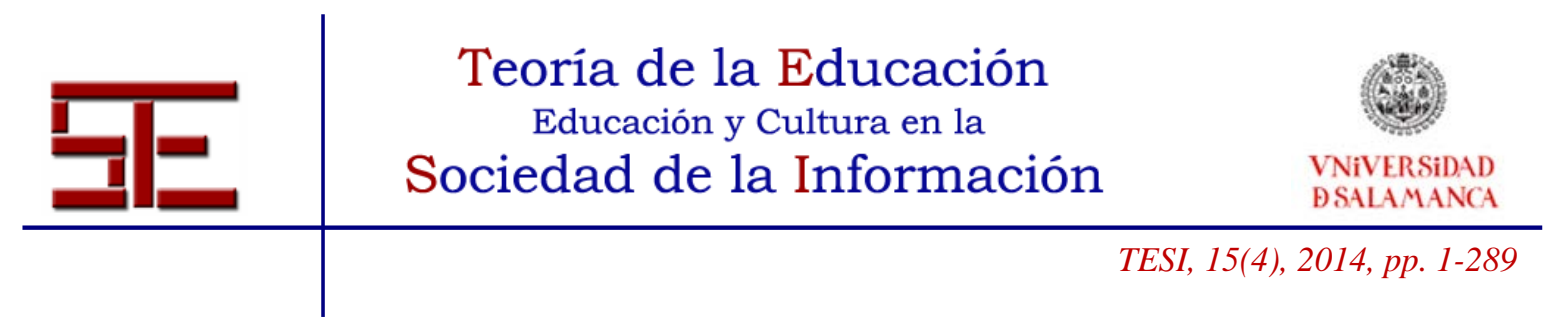

seauton. En este sentido, conviene recordar escritores y caminantes tan importantes como William Hazlitt o Robert Louis Stevenson, puesto que caminaron de una forma muy parecida, tal y como nos expresa la siguiente cita: "Una excursión a pie, para disfrutarla debidamente, debe hacerse a solas. Si se va en grupo, o incluso en pareja, ya sólo de nombre no es una excursión; es algo distinto, más bien de la índole de un picnic” (Hazlitt y Stevenson, 2003, 38).

Después, como es obvio, la naturaleza también jugó un papel muy relevante. Podríamos decir que los árboles y los animales serían sus únicos acompañantes mientras transitaba. Lo demuestran sus grandes descripciones paisajísticas ${ }^{2}$ y sus herbarios (Hortus siccus, jardín de plantas secas). Es evidente que el goce de descubrir y recolectar plantas fue muy importante para Rousseau durante sus últimos años de vida ${ }^{3}$ porque le permitió olvidar a sus enemigos (Diderot, D’Alembert, Voltaire) y, en consecuencia, soñar con la purificación de su vida que, al fin y al cabo, era su objetivo final durante aquella época.

A su vez, merece la pena destacar que la botánica es una ciencia que se vio favorecida por aquella voluntad prerromántica de querer convivir armoniosamente con la naturaleza tan típica de la sociedad de finales del siglo XVIII. Así pues, no podemos evitar señalar a autores tan importantes para la disciplina mencionada como Adanson, Jussieu o Buffon. De todos modos, es muy posible que el más importante de todos fuera el naturalista y médico Carl von Linné que, con su obra Sistema de los vegetables (1735), fundó la taxonomía moderna (nomenclatura binaria y sistema de clasificación sexual de las plantas).

Aún así, no podemos olvidar que Rousseau, si lo comparamos con el importante botánico sueco, dio un sentido muy diferente a la tarea de hacer herbarios recolectados durante sus campañas botánicas. Se trataba, pues, de un estudio ocioso realizado por un solitario que amaba la naturaleza sin propósitos instrumentales (no admitió que la botánica pudiera dividir en teórica y práctica) y, por este motivo, la presentó como una scientia amabilis para todas aquellas personas sensibles y curiosas por la variedad y complejidad del mundo vegetal. Según este filósofo, lo más importante de esta

\footnotetext{
${ }^{2}$ En el quinto paseo de su obra Las ensoñaciones del paseante solitario (93-109), el pensador suizo hace un retrato bucólico de la isla de Saint Pierre (el lago de Bienne, Suiza). Llegados a este punto, conviene recordar que la pintura, unos años más tarde, produjo una vasta obra de montañas, puestas de sol, valles, el mar o, lo que es lo mismo, sobre la relación del hombre con la naturaleza. Como sabemos, uno de los mejores paisajistas pictóricos (landscape) de la época fue Caspar David Friedrich. De este autor quería destacar Schweinfurt (1821), dado que aparecen dos caminantes -con parecidos más que evidentes con nuestro autor- contemplando la naturaleza en medio de un bosque estéticamente muy sugerente.

${ }^{3}$ Por orden cronológico, citamos algunos de los lugares donde realizó la actividad de herborizar: sierra del Jura, Val-de-Travers, isla de Saint Pierre, Estrasburgo, Derbyshire, Lyon, Grenoble, Bourgoin, Monquin y las afueras de París (bosques de Boulogne, Fontainebleau, Ermenonville y Montmorency). Además, en el libro Cartas sobre Botánica (2007b) se puede ver una estatua (página 6) y un grabado (página 12) que dan fe de su afición.
}

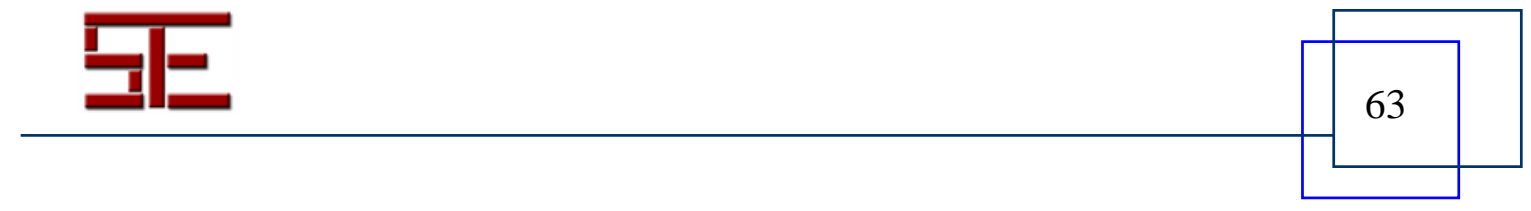




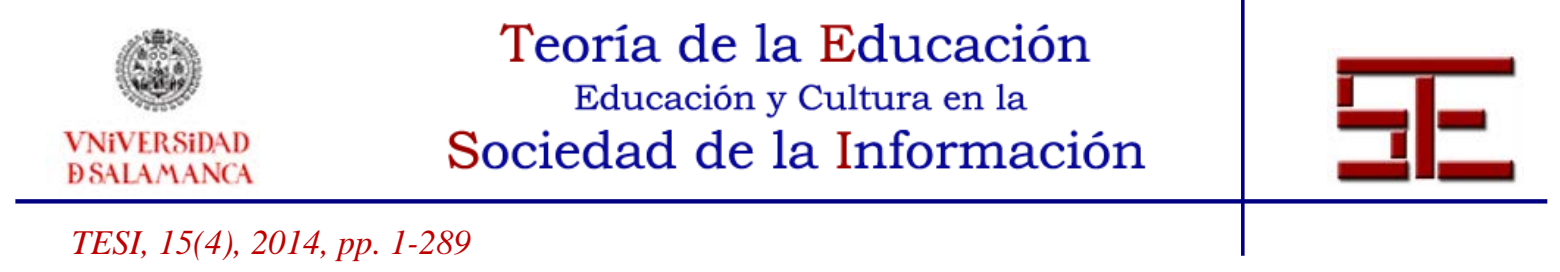

disciplina era saber observar la naturaleza y apreciar su belleza en lugar de aprenderse todos los nombres del reino vegetal de memoria. Una buena prueba de esta última idea son las Cartas sobre Botánica (1771-1778) porque, con un espíritu de divulgación científica indiscutible, presentó diferentes familias del reino vegetal (liliaceas, brasicáceas, leguminosas, lamiáceas o umbelíferas) a la petite Madelon, MargueriteMadeleine Delessert.

Por último, conviene recordar que el acto de soñar despierto (las Rêveries) también se convirtió en una de las singularidades relevantes del universo del Rousseau en movimiento. Para el autor de Du contrat social, el ensueño sub divo, que le permitía entretenerse y descansar a diferencia de la reflexión (Rousseau, 2008), fue la actividad más natural durante aquellos días. En cualquier caso, no hay ninguna duda de que, a pesar de la situación en que se encontraba, pasear le permitió poder pensar, recordar, poner orden a todas sus vivencias y sacar sus particulares conclusiones a partir de ideas ligeras, dulces y que no agitaran demasiado el fondo del alma. Finalmente, podemos añadir que esta actividad imaginativa era pasiva porque las ideas se sucedían sin obstáculos (sensibilidad física) pero, al mismo tiempo, todo lo contrario, porque era la guía de sus meditaciones.

En síntesis, acabamos afirmando que los paseos solitarios de Rousseau consistieron en un ensueño o una evasión por lo imaginario y un descubrimiento constante de plantas de las cercanías de París o las de la isla de Saint Pierre. Buena prueba de ello es el pasaje siguiente, que no hemos podido evitar reproducir íntegramente:

Nunca he podido hacer nada pluma en mano delante de una mesa y de mi papel. Es durante el paseo en medio de las rocas y los árboles, es de noche en mi cama y durante mis insomnios cuando escribo en mi cerebro: júzguese con qué lentitud, sobre todo para un hombre absolutamente falto de memoria verbal, y que en su vida no ha podido retener de memoria seis versos (Rousseau, 2007a, 153).

\section{2.- EI viaje cultural goethiano por tierras italianas (1786-1788): cuando se limitó a formarse artísticamente y científicamente}

¡A Roma -dijo-, a Roma tiene usted que ir si quiere ser algo! ¡Aquél es un mundo! En Alemania no podemos desligarnos de lo que hay de mezquino en nuestra naturaleza; pero tan pronto como entramos en Roma nos transformamos por completo y sentimos en nosotros la grandeza del ambiente. ¿Por qué no se ha quedado usted allí más tiempo?, pregunté. Se terminaron el dinero y el permiso -respondió-. Pero cuando puse el pie sobre los Alpes, dando la espalda a la bella Italia, sentí una emoción profunda (Eckermann, 2000, 233).

Antes de entrar en materia, consideramos conveniente hacer un par de comentarios previos con el propósito de contextualizar aquellos dos años dedicados a la observación de la naturaleza, de la historia o del arte por tierras italianas que, sin duda, supusieron un antes y un después en la vida de Goethe para dar forma a la figura del caminante que

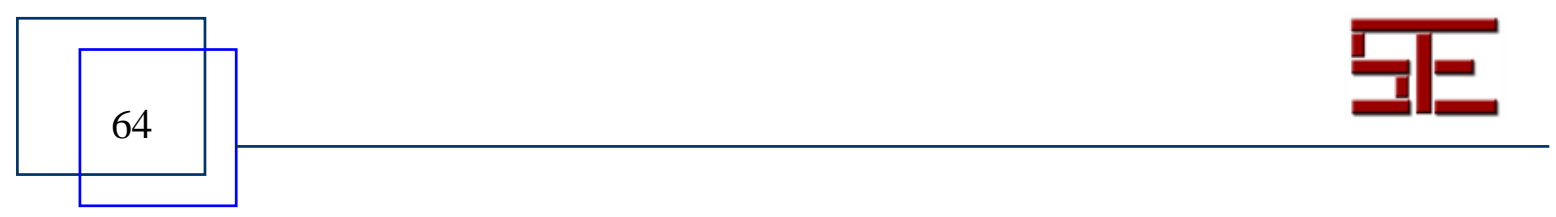




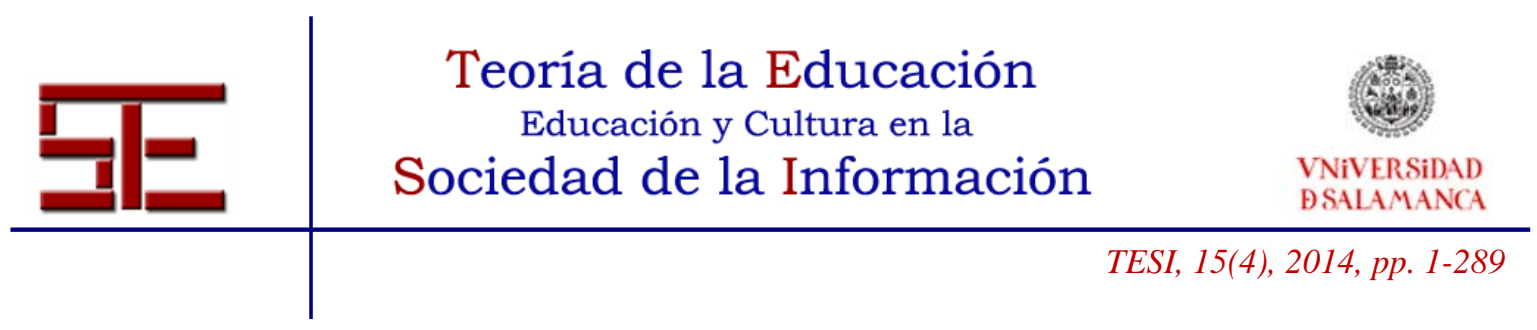

viaja con muy buenas maneras.

Por un lado, queremos decir que este afán de viajar por lugares desconocidos no debe extrañarnos puesto que, para el consejero de Weimar, esta práctica fue muy habitual a lo largo de su trayectoria biográfica, tanto debido a sus cargos políticos como por descanso, pero siempre con el propósito de que le aportaran nuevas enseñanzas culturales, espirituales, sociales y políticas. Son una buena prueba de ello sus excursiones a lugares como el Rin (1774), Suiza (1775, 1779, 1797), Harz (1777, 1783 y 1784) o Karlsbad (1785, 1786 y 1794). Y, por otro lado, destacamos su fuerte atracción por Roma desde edades muy tempranas, cosa que sin duda vino motivada por la influencia de su padre quien también visitó Italia en 1740. Como es conocido, tenía decorada una de las antecámaras con algunos de los recuerdos (una serie de panorámicas de la ciudad de Roma, una reproducción de una góndola veneciana o una colección de diferentes tipos de mármoles) de aquella experiencia (Goethe, 1999, 29) y se preocupó porque sus dos hijos supieran dominar la lengua italiana fluidamente.

Dicho esto y, después de que anulara la caminata hacia Italia en dos ocasiones estando en el Paso de San Gotardo, en 1775 y 1779, porque, según su parecer, todavía no tenía los conocimientos necesarios, el 3 de septiembre de 1786 fue cuando Goethe finalmente emprendió el viaje hacia el país de la Città Eterna a raíz de la unión de dos intereses totalmente personales: el deseo de frenar su fatiga motivada por el alud de responsabilidades aceptadas como funcionario de la corte de Weimar y la necesidad de tiempo y de libertad para reencontrarse con sí mismo y salvaguardar su espíritu creativo. Ahora bien, hay que constatar que esta nueva época empezó como si se tratara de una fuga, porque cruzó la frontera italianosuiza con una identidad inventada: Mr. Jean Philippe Möller, alemán y pintor.

En este sentido, no sobra recordar que Goethe narró este viaje al cabo de treinta años en una obra llamada Viaje a Italia, la cual forma parte de aquel género literario denominado literatura de viajes (Reiseliteratur) y que tiene el propósito de facilitar el interés y la curiosidad. Brevemente, podemos decir que este libro tiene dos partes claramente diferenciadas. En la primera, narra -siguiendo el formato clásico de los diarios de viajes- todos los hechos que le sucedieron en las diferentes ciudades italianas ${ }^{4}$ que visitó hasta el 3 de junio de 1787 y, en la otra, trata de su segunda estancia

\footnotetext{
${ }^{4}$ He aquí las ciudades visitadas durante estos dos años: Karlsbad, Zwota, Erger, Tirschenreuth, Ratisbona, Munich, Wolfrathshausen, Walchensee, Mittenwald, Brennero, Sterzingen, Brixen, Kollmann, Teutschen, Bolzano, Trento, Roveredo, Torbole, Malcesina, Verona, Vicenza, Pádua, Venecia, Ferrara, Cento, Bolonia, Giredo, Perusa, Florencia, Spoleto, Terni, Narni, Cìvita Castellana, Roma, Albamo, Genzano, Velletri, Fondi, Mola di Gaeta, Santa Ágata, Capua, Nápoles, Palermo, Alcamo, Segesta, Castelvetrano, Sciacca, Girgenti, Caltanisetta, Castrogiovanni, Catania, Taormina, Messina, Nápoles, Roma, Siena, Florencia, Módena, Parma, Piacenza y Milán. Dado que los grandes trayectos siempre fueron efectuados en coches de caballos o incluso en barco, debemos aclarar que la faceta más pedestre de Goethe siempre
}

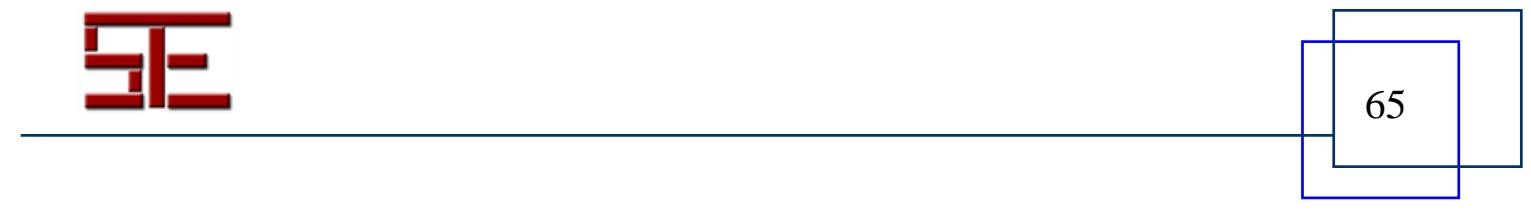




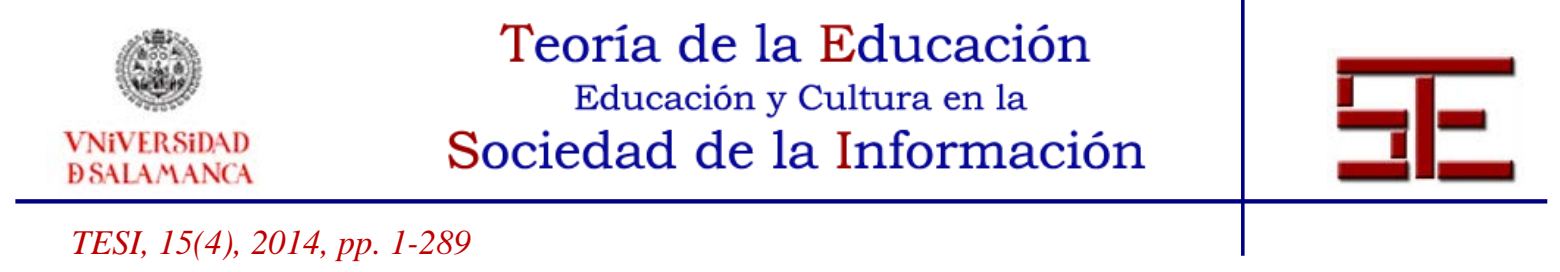

en Roma (desde el 7 de junio de 1787 hasta el 14 de abril de 1788) a través de un diario y otros géneros literarios (correspondencia recibida e informes que valoran el paso del tiempo).

Sea como fuere, lo que es en todo caso incuestionable es que estamos ante un viaje cultural por antonomasia porque es innegable que fue un recorrido lleno de formación e investigación que nosotros ordenamos en tres bloques con la intención de que nuestra explicación sea mucho más clara y entendedora. Así, pues, podemos decir que el deseo insaciable por saber de Goethe se focalizó en la belleza clásica, las artes plásticas y las ciencias naturales durante aquellos años.

Para empezar, destacamos que la capital de Italia se convirtió en la puerta de la tradición clásica para nuestro autor (Roma, caput mundi!). Sin duda, vino motivado por la obra de Andrea Palladio, que estudió y visitó durante sus paseos venecianos (el Convento della Carità, la iglesia del Redentore y otros) $\mathrm{y}$, asimismo, por la lectura de libros tan importantes como Historia del Arte de la Antigüedad (1764), de Johann Joachim Winckelmann, que fue un hombre apasionado por el arte helénico. Por lo tanto, podemos decir que, a raíz de la repulsión hacia la generación del Sturm und Drang y de este periplo italiano, el arte antiguo -o sea, el arte griego- se convirtió en el único que llenaba su deseo de claridad y serenidad, porque tanto el Renacimiento ${ }^{5}$ como el Barroco (Francesco Borromini) le interesaron muy poco. Este hecho fue fundamental para la definición de sus ideales clásicos que, años más tarde y junto a su amigo Schiller, se convirtió en el Weimarer Klassik.

Otra cuestión importante de esta experiencia fue su anhelo de convertirse en un notable pintor, lo que evidencia que durante aquellos años el autor de Werther todavía no había descubierto que su principal talento era la escritura en vez del dibujo. Sin embargo, Goethe se concentró en esta empresa durante aquellos dos años visitando diferentes galerías artísticas (la San Giorgio y Gherardini de Verona, la Colona y la Borghese de Roma y otras), elaborando una gran cantidad de acuarelas con la intención de captar la belleza artística de los lugares visitados (excursiones pictóricas) y, además, discutiendo sobre cuestiones de arte con diferentes artistas alemanes (Christian Heinrich Kniep, Karl Philipp Moritz, Johann Heinrich Tischbein, Angelika Kaufmann, Johann Heinrich Meyer, y otros) que estaban instalados en Italia siguiendo el sendero del sur clásico.

Y, por lo que se refiere a su formación científica, podemos decir que, cautivado por la luz mediterránea, se interesó por múltiples aspectos de orden natural. Es decir: la botánica (herborización, colección de flores, visita del Jardín Botánico de Padua y

debemos situarla en las estancias que hizo en las ciudades de Verona, Venecia, Ferrara, Bolonia, Nápoles, Palermo y, por supuesto, Roma.

${ }^{5}$ Una prueba elocuente de esta voluntad es que su estancia en Florencia tuvo una duración de tan solo tres horas el día 25 de octubre de 1786, enfrente de un total de catorce meses, en dos etapas, en la ciudad de Roma. Véase GOETHE, J. W. (2009): Viaje a Italia. Barcelona, Ediciones B, 123-130.

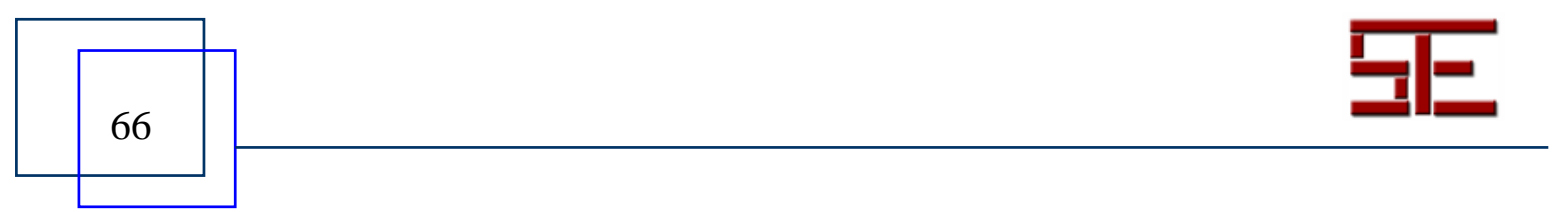




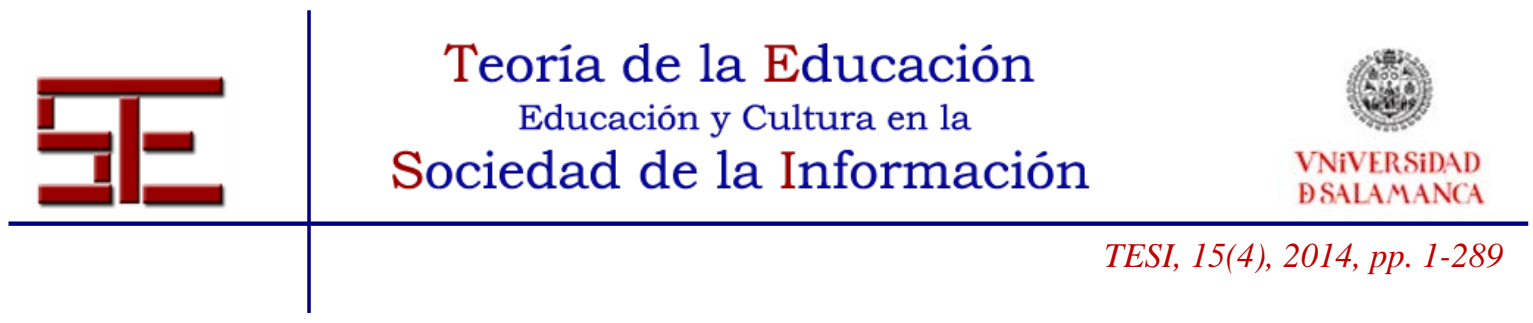

descripción -por primera vez- del posible desarrollo de una planta original o arquetípica -Urpflanze- que incluye las características de todas las otras cuando estaba en Nápoles), a pesar de que se enfrentó a Linné porque no le gustaban las taxonomías; la meteorología (forma y formación de nubes, dirección de los vientos, lluvias); la biología (fauna y flora marítima después de ver el mar por primera vez en Venecia) o la geología (recogida de minerales, interés por la forma de las montañas y visita del volcán Vesubio). Por lo tanto, sostenemos que esta experiencia también fue una de las más importantes de la trayectoria vital de Goethe desde esta perspectiva porque resultó muy inspiradora para obras posteriores como por ejemplo La metamorfosis de las plantas (1790).

Concluimos el relato de esta experiencia pedestre diciendo que, además de este enriquecimiento clásico, artístico y científico tan importante para el crecimiento intelectual de Goethe, no podemos olvidarnos que, durante aquella singladura italiana, este viajero de espíritu abierto también volvió a escribir (reencuentro con su alma más creativa) después de hacerlo solamente de manera fragmentaria durante la época que coincidió con su primera estancia en Weimar (1775-1786). En consecuencia, remarcamos las obras de teatro y de poesía elaboradas en aquellos tiempos, que hacían realidad la consigna neohumanista que proclamaba el regreso a los clásicos para recomponer la armonía helénica: Ifigenia en Táuride (1787), Egmont (1788) o Torquato Tasso (1790) y Elegías romanas (1795).

Así pues, este viaje cultural supuso para Goethe un importante cambio de rumbo estético con el descubrimiento del espíritu clásico y, al mismo tiempo, una inmensa sensación de felicidad gracias a la libertad experimentada y el aprendizaje tan profundo conseguido, que lo impulsó a continuar con sus aficiones literarias y científicas. Fue éste un viaje cultural que ejerció sobre Goethe un milagroso efecto rejuvenecedor.

\section{3.- Caminatas e inspiraciones nietzscheanas (1879-1889): las vivencias intelectuales de Chasté y de la roca de Surlei}

Por la mañana yo subía en dirección sur, hasta la cumbre, por la magnífica carretera que va hacia Zoagli, pasando junto a los pinos y dominando ampliamente con la vista el mar; por la tarde, siempre que la salud me lo permitía, rodeaba la bahía entera de Santa Margherita, hasta llegar detrás de Portofino. [...] En estos dos caminos se me ocurrió todo el primer Zaratustra, sobre todo Zaratustra mismo en cuanto tipo: más exactamente, éste me asaltó.... (Nietzsche, 1971, 95).

Antes que nada, conviene señalar que, a partir de ahora, solo mencionaremos la forma de caminar que Nietzsche llevó a cabo durante los años de errancia ${ }^{6}$ y de soledad casi

\footnotetext{
${ }^{6}$ Con el objetivo de que su recorrido sea más sencillo y legible, mostramos todas las ciudades transitadas durante aquella época. En definitiva: Wiesen, St. Moritz, Chur y Naumburg (1879); Bozen, Basilea, Riva, Venecia, Corintia, Tirol, Marienbad y Naumburg (1880); Frankfurt, Heidelberg, Locarno, Stressa, Génova, Venecia, Recoaro, Sils-Maria, Génova, Breve y Montecarlo (1881); Génova, Messina, Génova,
}

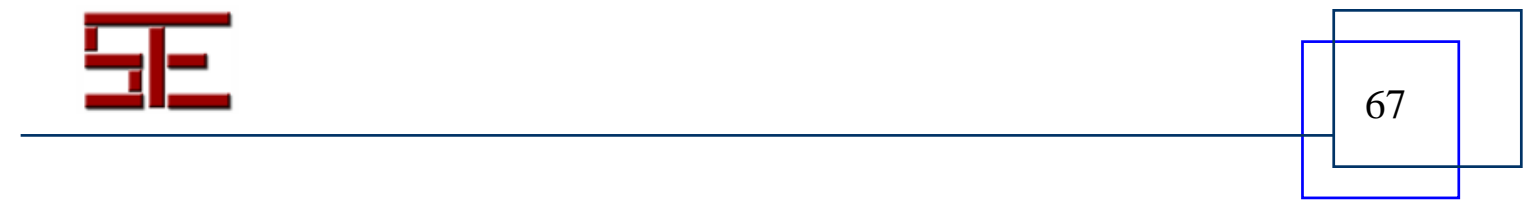




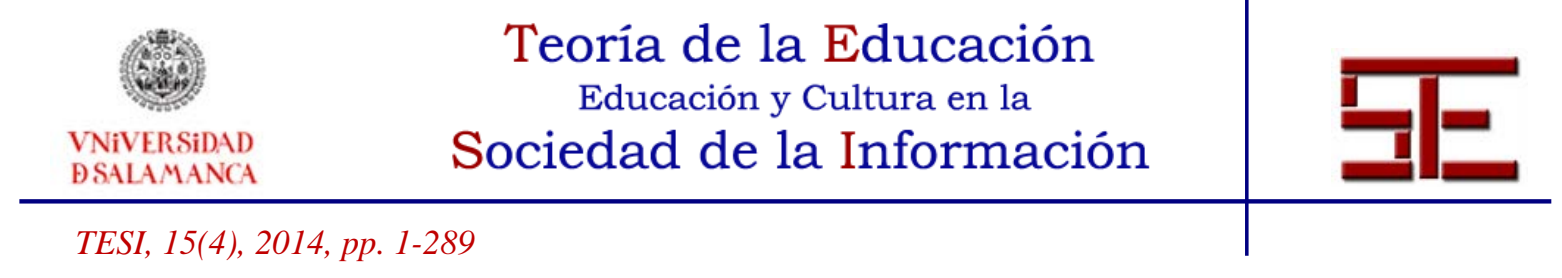

completa salvo contadas amistades filosóficas (philosophischen freuden). También es cierto que durante aquella etapa fue cuando este filósofo alemán escribió la mayor parte de su obra (sabiduría en plenitud) ${ }^{7} \mathrm{y}$, asimismo, encontró sus ideas más capitales mientras daba un paso detrás de otro. Nos estamos refiriendo a la doctrina del eterno regreso y a la imagen de la figura de Zaratustra. Aun así, cabe decir que este nomadismo intelectual siempre estuvo presente a lo largo de su trayectoria vital porque sus intereses eran de una diversidad casi infinita. En este sentido, no podemos desterrar el ejemplo de estas dos revelaciones, dado que nos brinda una oportunidad excelente para tratar dos elementos muy importantes en la vida de este Freigest: por un lado, su forma de transitar, que resultó muchos más ligera después de huir de la solemnidad académica y de la cultura del espectáculo (Parsifal de Richard Wagner) y, de otro, el tema de la inspiración, que consiguientemente nos llevará a hablar de su proceso creativo.

He aquí los paseos de Nietzsche, que siempre se llevaron a cabo en momentos muy concretos del día, y formaban parte asimismo de una triple elección que era propia de un tipo de hombre que él consideraba de buena constitución (Nietzsche, 1971). Es decir: el tipo de alimentación (vegetarianismo), el clima (mucha presencia del sol y aire seco), lugares de residencia (la costa genovesa, Sils-Maria y Turín) y, en último lugar, la recreación, que no era otra cosa que el acto de caminar y la lectura insaciable de obras muy diversas. En cualquier caso, podemos destacar que estas dos últimas ocupaciones fueron incompatibles, dado que durante sus paseos reveladores por Sils-Maria o la costa genovesa nunca iba acompañado por un libro.

Vemos, pues, que el acto de caminar, según este pensador alemán, era un momento óptimo para pensar por uno mismo y no a partir de otro, como ocurre cuando se está leyendo una obra. Nietzsche lo expresó con estas palabras tan brillantes: "No somos de esos que sólo rodeados de libros, inspirados por libros, llegan a pensar -estamos acostumbrados a pensar al aire libre, caminando, saltando, subiendo, bailando, de preferencia en montañas solitarias o a la orilla del mar, donde hasta los caminos se ponen pensativos” (Nietzsche, 2009, e t291).

En otro orden de cosas, conviene destacar el proceso creativo, porque sus paseos a menudo los hacía para obtener una dosis de inspiración como ha sucedido en otros

Roma, lago de Orta, Monte Sacro, Locarno, Lucerna, Tribschen, Basilea, Naumburg, Tautenburg, Naumburg, Leipzig, Basilea, Génova, Santa Margherita y Rapallo (1882); Génova, Roma, L’Alquila degli Abruzzi, Sils-Maria, Naumburg, Basilea, La Spezia, Génova y Niza (1883); Venecia, Basilea, SilsMaria, Zürich, Menton y Niza (1884); Venecia, Sils-Maria, Naumburg, Munich, Leipzig y Niza (1885); Venecia, Munich, Leipzig, Sils-Maria, Génova, Roca Ligure y Niza (1886); Cannobio, Brestenberg Castle, Zürich, Chur, Sils-Maria, Venecia y Niza (1887); Génova, Turín y Sils-Maria (1888) y, por último, Turín (21 de septiembre-9 de enero.

${ }^{7}$ Durante su etapa errante, publicó un total de diez libros: El paseante y su sombre (1880), Aurora (1880), La Gaya ciencia (1882), Más allá del bien y del mal (1886), La Genealogía de la moral (1887); y, escritos durante 1888: El caso Wagner, El ocaso de los ídolos, El anticristo y Ecce Homo.

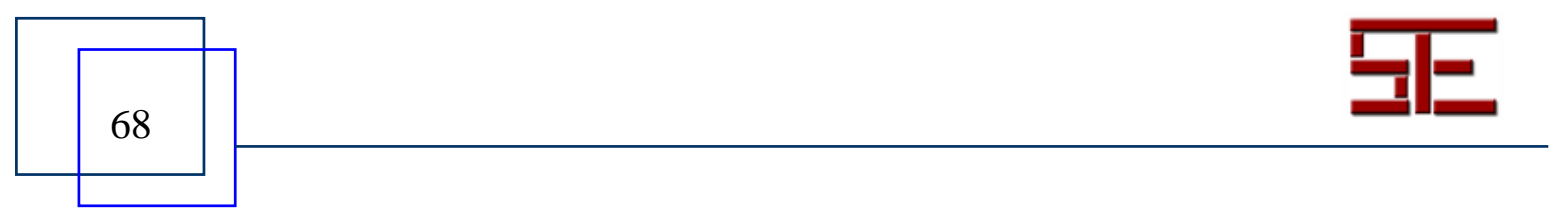




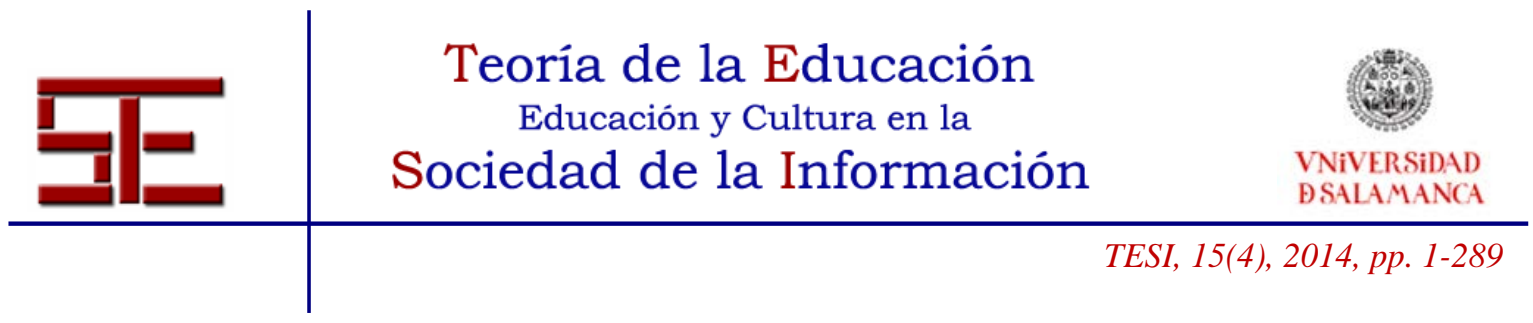

autores (Erik Satie). Dicho esto y, una vez establecida esta idea, ahora parece oportuno recordar los lugares donde le visitó la inspiración. Hablando de forma específica, diremos que la figura de Zaratustra irrumpió entre Rapallo y una pequeña península que se encuentra en el lago de Sils, llamada Chasté, que le gustaba mucho a Nietzsche. Actualmente se puede encontrar una placa conmemorativa en una de las rocas de Chasté con la inscripción del Canto del noctámbulo (Nietzsche, 2008). En cuanto a la doctrina del eterno regreso, todo ello ocurrió en una de las rocas existentes en Surlei (1881).

Así, por lo tanto, no hay duda de que la idea es muy clara y sencilla: la inspiración nietzscheana, que relató como una experiencia similar a un éxtasis o una tormenta de sensación de libertad, fue pedestre y formaba parte de una forma de trabajar que consistía en caminar, pensar, anotar y desarrollar los temas en casa, pero sin buscar las ideas porque éstas deben aparecer, deben irrumpir. Dicho de otro modo: los paseos nietzscheanos son una especie de estados fisiológicos estéticos porque son de una extrema agudeza y vivacidad de todos los sentidos.

Llegados a este punto, consideramos que es el momento oportuno para hacer un pequeño comentario sobre su forma de filosofar o sobre la forma en que descubría sus conceptos clave. Desde nuestra perspectiva, existen dos puntos fundamentales en esta forma de ser que podríamos definir con el epígrafe de vivencia intelectual ${ }^{8}$. Por un lado, sostenemos que es muy evidente que Nietzsche siempre se dejó despeinar por el viento de Suiza o de la costa mediterránea mientras filosofaba, por lo cual, su pensamiento siempre fue vivido como un sentimiento y sin distancia entre lo dicho y lo vivido. Por lo tanto, no nos debe extrañar si afirmamos que la vida resultó un medio apto para el desarrollo de su conocimiento (Nietzsche, 2009) y, en consecuencia, sus inspiraciones se produjeron lejos de despachos racionalistas y sistemáticos y dieron relevancia a lugares tan sorpresivos como son los casos que hemos mencionado antes. En definitiva: la filosofía no es algo "que se estudia, que se capta y comprende en una especialidad del saber, a ser posible amplia, sino una actitud espiritual, una tarea, una vivencia, que lo llenaba completamente y comprendía en sí, diluía, abarcaba, todo saber meramente particular” (Janz, 1978, 130).

\section{HACIA UNA PEDAGOGÍA QUE VINCULE CAMINAR Y FORMACIÓN}

A la vista de lo anterior, a continuación queremos dejar constancia de las bases conceptuales de una pedagogía que vincule caminar y formación tal y como estamos defendiendo como tesis en este artículo. De ahí que a continuación abordaremos el

\footnotetext{
${ }^{8}$ El cuadro Munch museet (1906) de Edvard Much ilustra perfectamente esta idea que acabamos de expresar.
}

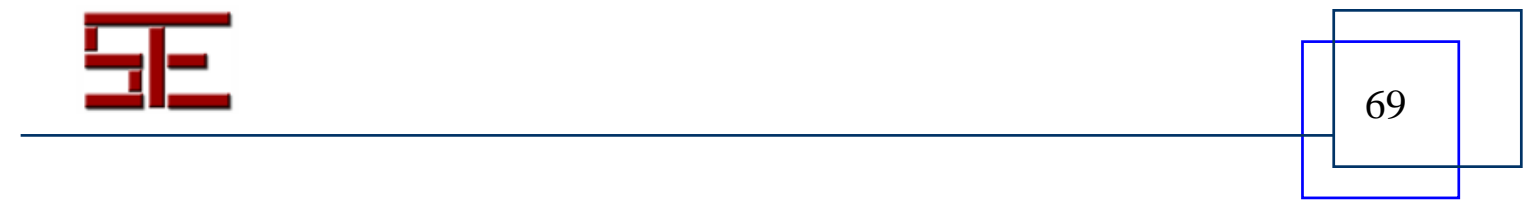




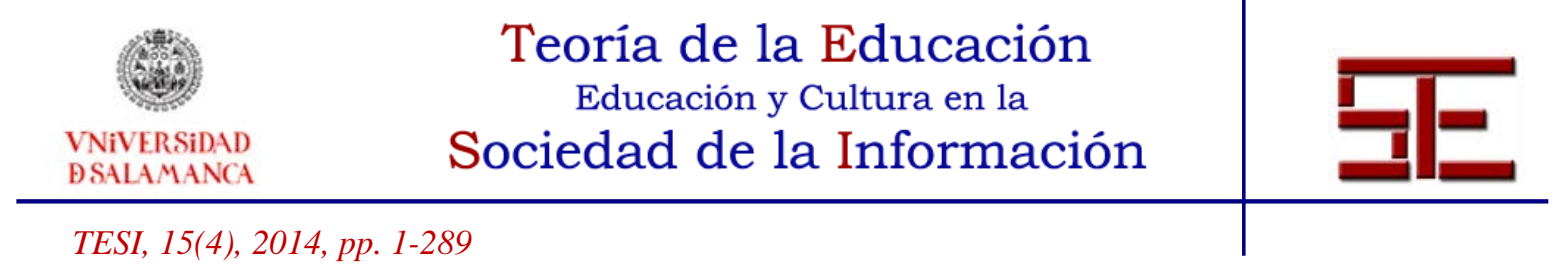

asunto del neonomadismo pedagógico de Juan Tusquets como núcleo central y, asimismo, citaremos diferentes prácticas, tanto heteroeducativas como autoformativas, que utilizan el acto de caminar como método educativo desde diferentes cosmovisiones pedagógicas (naturalismo, culturalismo y postestructuralismo). Valga recordar que los paseos rousseaunianos, el viaje cultural goethiano y las caminatas nietzscheanas continuaran guiándonos en el desarrollo de este apartado.

\section{1.- EI neonomadismo pedagógico}

Parece claro, pues, que, para entender completamente este caminar educativo es necesario comentar las diferentes formas de vida colectiva aparecidas a lo largo de nuestra historia. Juan Tusquets, que publicó el libro Tarzán contra Robot. El neonomadismo y el neosedentarismo protagonistas de la crisis contemporánea (1986), desarrolló una interesante interpretación histórica sobre este asunto: del nomadismo del hombre primitivo pasamos al sedentarismo neolítico de la cultura agrícola, la cual se reforzó con el neosedentarismo de la sociedad industrial que, más adelante, dio lugar al neonomadismo de la sociedad postindustrial actual.

Siguiendo con el mismo autor, ahora es el turno de abordar el neonomadismo y el neosedentarismo pedagógico aprovechando su metáfora de Robot (símbolo del neosedentarismo) y Tarzán (héroe del neonomadismo), que tenía el objetivo de conciliar estos dos extremos. En cuanto a la primera opción, diremos que privilegia la escuela como único recurso educativo a través de las contribuciones de Bell y Lancaster, el plan Dalton o las fichas Dottrens (Tusquets, 1983-1984). En cuanto a la segunda, que, a grandes rasgos, pretendía combatir la escolarización imperante, el profesor Tusquets establece la siguiente clasificación: por un lado, las no revolucionarias (el escultismo de Baden-Powell y la escuela nueva) y, por otro, las revolucionarias (las comunidades libres escolares - Freie Schulgemeneinde - de Gustav Wyneken, el movimiento de los Wandervögel e Ivan Illich) (Tusquets, 1981-1982, 207-223).

Dicho esto, consideramos que no hay duda de que esta pedagogía también incorpora las principales tesis del nomadismo pedagógico (pluralismo, activismo, participación, aprendizaje espontáneo e informal, y carencia de edificios y utillajes escolares) porque toda su acción sucede in itinere y al aire libre. Consecuentemente, podemos entender esta teoría de la formación humana como aquella que nos saca de la quietud, de la perennidad y de todo aquello que nos hace ser dependientes en el aspecto educativo para entregarnos a los azares del camino, del clima, de los encuentros y de los pensamientos más bien poco sistemáticos.

\section{2.- Prácticas heteroeducativas naturalistas: escultismo, excursionismo escolar}

No hay duda de que tanto el excursionismo escolar como el escultismo nos obligan a hacer un pequeño comentario sobre el naturalismo pedagógico $\mathrm{y}$, por lo tanto, de Rousseau. Es bien sabido que el Emilio, o De la educación es la señal de la primera

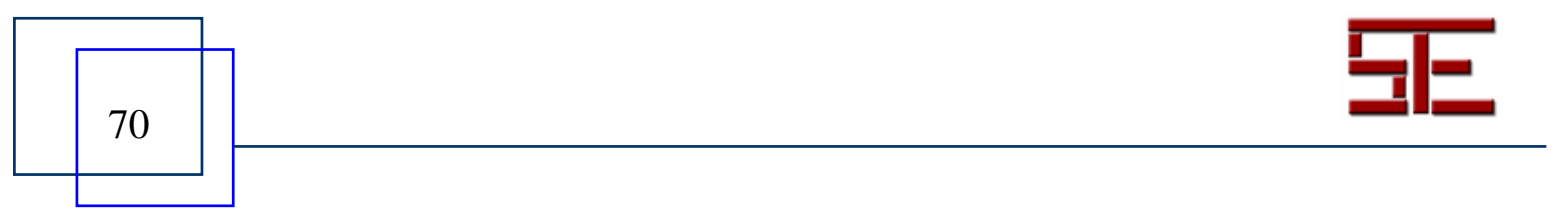




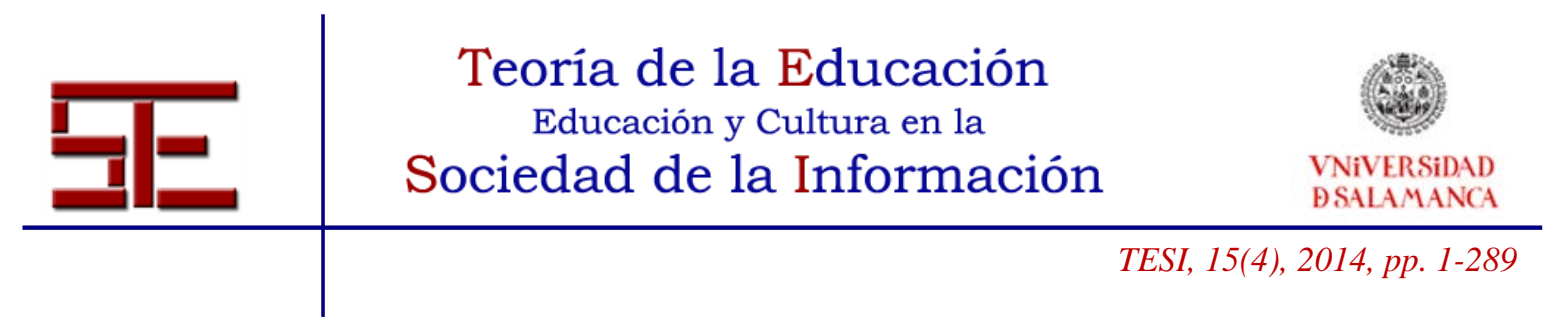

teoría de la modernidad pedagógica que surge como reacción al formalismo racionalista de aquella época planteando un método cuyo objetivo es lograr la pureza del ser humano con la supresión de toda la maldad acumulada por la cultura artificiosa y la desigualdad humana.

De esta forma, podemos decir que Rousseau propuso una nueva Ilustración que enfatizaba el papel de la educación natural tal y como hemos podido comprobar con su forma de caminar. A grandes rasgos, tenía la pretensión de reconciliar el hombre con la naturaleza (Retournons à la nature!), promover un optimismo antropológico (el hombre es bueno por naturaleza y es la civilización la que lo corrompe) ante un pesimismo social e histórico, exaltar el ejercicio físico y el contacto con la naturaleza (el gusto por el pleinairismo) y, además, construir una pedagogía vivida y espontánea para que el niño pueda experimentar por sí mismo y no a través de los demás (individualismo).

Tal y como especifica Michel Söetard (1995), esta concepción naturalista de la educación tuvo una muy buena acogida -con lógicas restricciones, es el caso del papel de la sociedad y la cultura- entre los llamados pedagogos del Romanticismo (Pestalozzi o Fröebel) y, posteriormente, en los principales representantes del movimiento renovador de la Escuela Nueva (Montessori, Ferrière, Decroly o Dewey y otros). Así que no nos puede extrañar que prácticas como el escultismo o el excursionismo escolar tenga una estrecha relación con esta tendencia pedagógica.

Sobre el escultismo, podemos decir que Robert Stephenson Smyth Baden-Powell (18571939), cuando era comandante de la ciudad de Mafeking y estaba siendo asediada por el ejército boer (1899-1900), fundó un cuerpo de cadetes con chicos de 13 a 15 años con funciones logísticas relacionadas con la guerra (mensajería, preparación de comidas, etc.) y, al cabo de poco tiempo, dirigió el primer campamento en la isla de Brownsea (Inglaterra, 1907). No podemos olvidar que, fruto de aquella experiencia, escribió Escultismo para muchachos (1908), que se convirtió en el manual de un nuevo movimiento juvenil educativo como es el escolta, que hoy en día todavía tiene mucha vigencia.

La vida al aire libre y la vinculación con la naturaleza también se convirtieron en elementos primordiales en este método. Dejemos hablar, para expresarlo mejor, a Baden Powell: "la vida al aire libre, del cual un scout no puede librarse una vez ha caído bajo su influjo. El hombre que ha crecido entre las grandes obras de la naturaleza, cultiva de verdad la independencia y la confianza en sí mismo; tiene impulsos generosos, es leal con sus amigos y con la bandera de su patria” (Baden Powell, 1976, 48). He aquí, pues, que este posicionamiento a favor del pleinairismo hizo que diferentes autores del movimiento de la Escuela Nueva (Adolphe Ferrière, entre otros) considerasen la propuesta de este militar inglés como la representación más ilustre fuera de la escuela propiamente dicha.

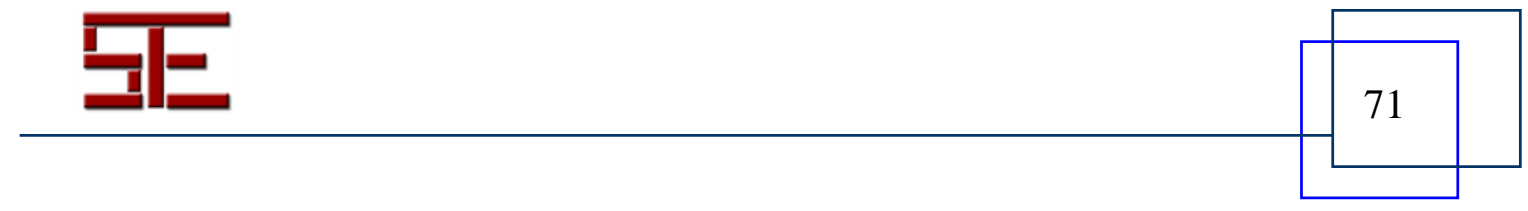




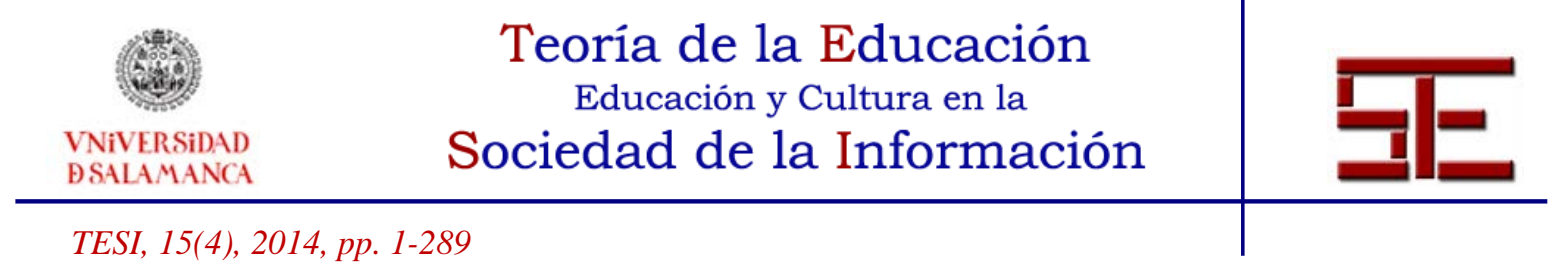

En todo caso, el escolta que tenía en mente Baden-Powell tenía que ser una persona que practicase actividades físicas o deportivas en la naturaleza y se esforzara para conocer los nombres de las plantas recogiendo hojas, frutos o flores para examinarlos, coleccionando hojas de diferentes árboles, averiguando qué plantas salvajes servían de alimento y, además, buscando plantas. Aun así, no podemos perder de vista algo fundamental: esta actividad tiene claras connotaciones regeneracionistas $y$, consiguientemente, patrióticas. Podemos decir que el escultismo es un gran juego al aire libre (Baden Powell, 1976) con el objetivo de formar personas libres y capaces de valerse por ellas mismas. En las páginas del Escultismo para muchachos queda muy explícito su método: fortalecimiento de la salud física y la inteligencia; desarrollo del carácter (character factory), que representaba el sentido del honor, de la responsabilidad $\mathrm{y}$ de la fidelidad a los compromisos adquiridos $\mathrm{y}$, por último, la disposición de servir a los demás (Be prepared!). En resumen: no hay duda de que el escultismo puede ser considerado una escuela de ciudadanía activa.

En torno al excursionismo escolar, hay que poner de manifiesto que también se convirtió en una de las prácticas con mayor trascendencia educativa en los movimientos de renovación pedagógica debido a su concepción totalmente paidocéntrica y activa. Situando la obra de Rousseau como punto de partida de esta cosmovisión pedagógica, no hay duda de que Johann Bernhard Basedow (1724-1790), Johann Heinrich Pestalozzi (1746-1827) y Friedrich Fröbel (1782-1852) representan los primeros antecedentes claros del excursionismo escolar.

En cuanto al primer pedagogo citado, podemos decir que en su escuela (Philanthropinum) llevó a cabo diferentes actividades al aire libre, como las excursiones para aprender la geografía o naturaleza local e, incluso, campamentos de verano con una duración de uno o dos meses. En relación con el gran educador suizo, destacamos que su tesis sobre la intuición sensible contribuyó significativamente a la difusión de los paseos escolares porque considera que toda educación debe fundamentarse en la experiencia directa que proporciona la realidad. Por último, encontramos las siguientes palabras de Fröbel defendiendo pedagógicamente las excursiones y los viajes por la naturaleza que, como es muy conocido por todo el mundo, contribuyeron significativamente a su difusión posterior:

Es así, por este método de descubrimiento, por la propia consideración de la continua y viviente unidad de la Naturaleza (y no por palabras y explicaciones conceptuales, que no son comprendidas por el niño) como se desenvuelve y se aclara cada vez más por obscuro que sea al principio, el pensamiento grandioso de la unidad interna, viva y continua de todas las cosas y de todos los fenómenos de la naturaleza. (Fröbel, 1913, 396).

Por consiguiente, no puede extrañarnos que la mayoría de pedagogos ilustres de la Escuela activa incorporaran la práctica del excursionismo en la escuela a principios del

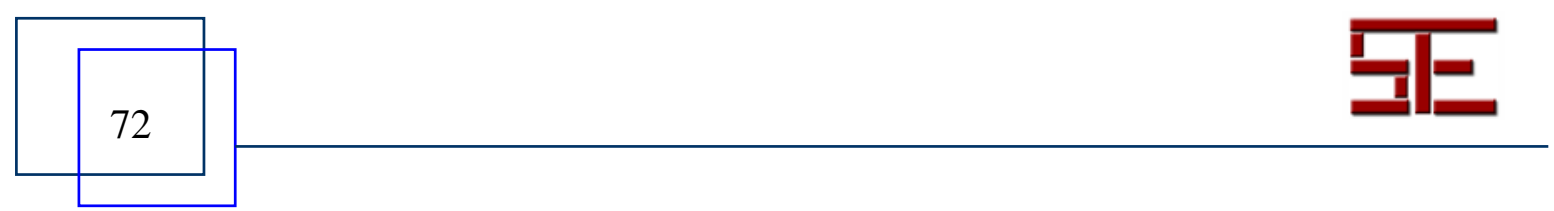




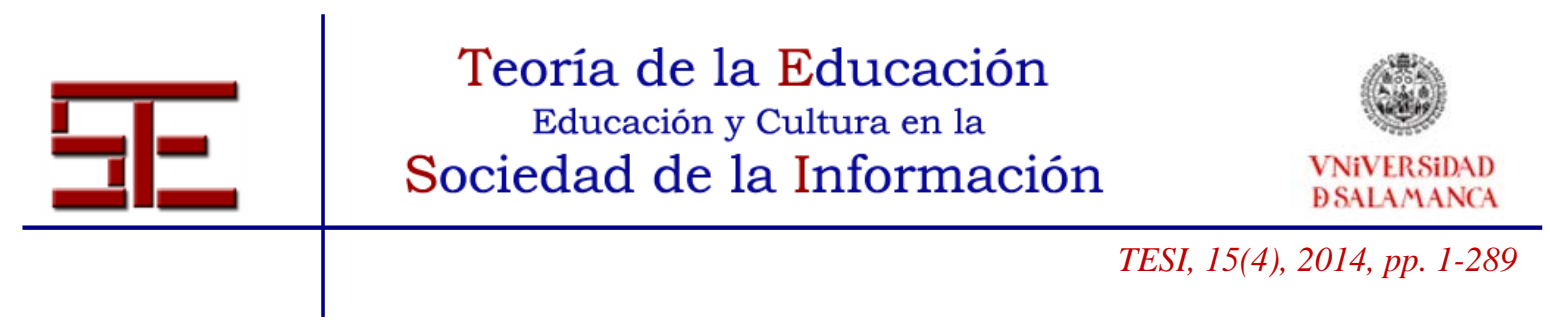

siglo XX. De hecho, resultó un complemento fundamental para el aprendizaje de algunas materias, principalmente aquellas que se refieren al medio natural, social y cultural, puesto que sirve para ilustrar perfectamente el temario de las asignaturas $\mathrm{y}$, al mismo tiempo, permite el contacto directo con el paisaje, poblaciones o monasterios, haciendo despertar la curiosidad a los alumnos. Llegados a este punto, destacamos, a guisa de ejemplo, las clases-paseo que llevaba a cabo Célestin Freinet (1896-1966) después de comer para observar diferentes oficios o aspectos de la naturaleza (Freinet, 1976).

En esta línea, también se podría añadir que la pedagogía socialista de orientación anarquista consideró asimismo el excursionismo como una herramienta pedagógica de primer orden. Buena prueba de ello son las experiencias educativas de Liev Tolstói (1828-1910) en la escuela Yasnaia Poliana (Tolstoi, 1978) y, especialmente, de Francesc Ferrer i Guàrdia (1959-1909), porque cuando visitaba fábricas con su grupo escolar siempre añadía una fuerte carga ideológica a su práctica educativa, un aspecto que en el resto de experiencias que hemos mencionado no está presente (Ferrer Guàrdia, 2010).

\section{3.- Viaje cultural, una práctica autoformativa y heteroeducativa}

Junto con los hermanos Humboldt y otros nombres, hay que decir que Goethe fue uno de los principales autores del neohumanismo alemán (1780-1830), el cual fue posible gracias al entronque entre los humanismos del Renacimiento y el que surgió del Aufklärung (Ilustración). Como es de sobra conocido, la creación más genuina de este movimiento renacentista que ha acabado convirtiéndose en un pilar fundamental de la pedagogía germánica contemporánea es la Bildung, es decir, el sueño ilustrado de una educación tolerante, racional y humanista que, desde un optimismo pedagógico, pretendía convertir a los seres humanos más ricos en experiencia y conocimientos. Por este motivo, hay que vincular el culturalismo pedagógico con la concepción de la educación como Bildung que, a pesar de sea de difícil traducción, siempre debe ir asociada tanto a la formación como la cultura.

He aquí, pues, el ideal educativo alemán contemporáneo por excelencia que, junto con la Paideia, Humanitas, Studium o Sapientia, representa una de las vías pedagógicas de Europa. Merece la pena recordar que se trata de un concepto que proviene del movimiento burgués que, atraído por el arte clásico, establece una estrecha relación con la Paideia, dado que proclamó aquello tan conocido de Bilde dich griegisch (Fórmate como un griego). Lo que en todo caso es incuestionable es que la Bildung ha tenido un largo recorrido en la historia de la pedagogía, y su legado ha llegado, a pesar de varias interrupciones (Vilanou, 2001), hasta una de las líneas discursivas que se perciben en el panorama actual, es decir, la pedagogía hermenéutica, porque considera que la formación tiene algo personal e individual que se analiza por medio de un proceso de autointerpretación.

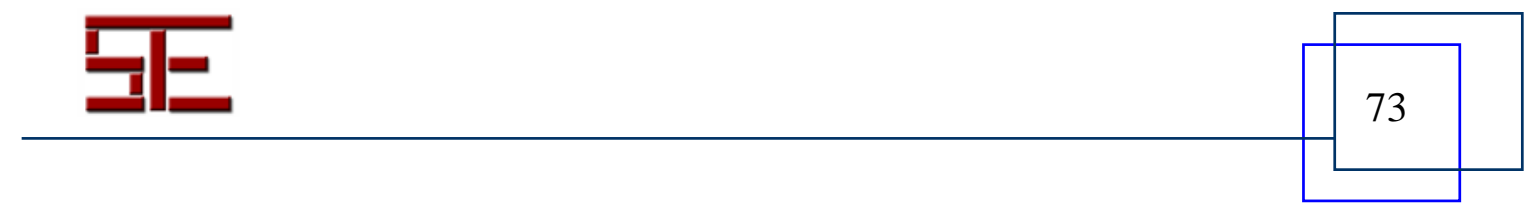




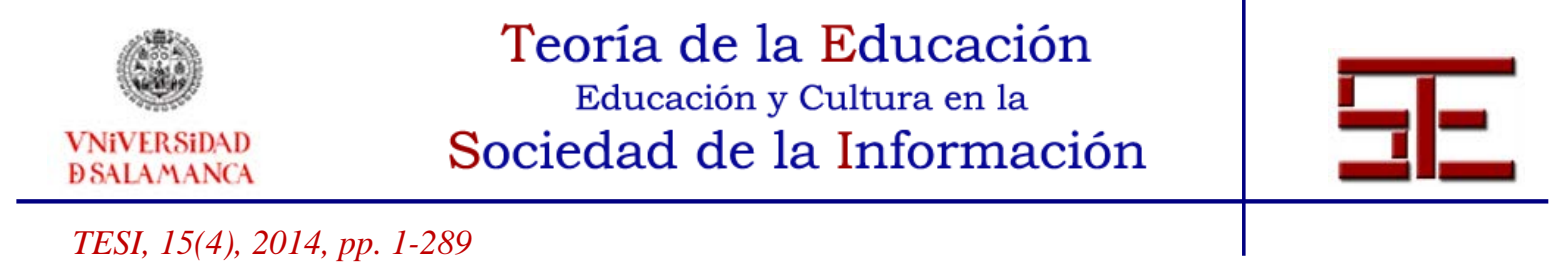

Tomando como hilo conductor la Bildungsroman (novela de formación), pasamos a detallar el viaje cultural como práctica autoformativa. Como es conocido, es uno de los estilos literarios alemanes por excelencia, que se inició con el libro Los años de aprendizaje de Wilhelm Meister (1777-1829) que, al mismo tiempo, plantean una formación entendida como la posibilidad de vivir, desde un horizonte individualista y burgués, una verdadera metamorfosis lejos de la educación institucionalizada y, por encima de todo, un proceso en que el sujeto debe participar activamente en su propia educación. De este modo, no hay duda de que su principal aportación es el deseo de descubrir interior y espiritualmente los métodos mediante los cuales se podían despertar todas aquellas fuerzas dormidas para dirigirlas hacia una actividad beneficiosa o un conocimiento de la realidad.

Dicho esto, es el momento de recordar que el viaje cultural que Goethe emprendió a tierras del clasicismo forma parte de una tradición que surgió a partir del siglo XVI originando, no obstante, dos maneras muy diferentes de llevarlo a cabo. En primer lugar, destacamos el Grand Tour, que eran aquellos itinerarios iniciáticos que realizaban los hijos de muchas familias influyentes de Europa, como aristócratas y burgueses ricos de Alemania y de Gran Bretaña principalmente, después de acabar los estudios universitarios. Cabe decir que este viaje perseguía objetivos como el de buscar las fuentes de la cultura, estudiar lenguas extranjeras y adquirir una mayor sabiduría para la vida (conocer mundo) porque de este modo, estos viajeros (Kavalierstour) podrían convertirse en brillantes estadistas, diplomáticos, funcionarios, profesionales, comerciantes o banqueros en el futuro.

Aun así, conviene añadir que este afán por viajar a Italia no fue solamente patrimonio de estos adolescentes de buena familia, puesto que la figura del gentleman traveller, es decir, diferentes científicos, artistas o humanistas guiados por la curiosidad del descubrimiento, también emprendieron este camino para redondear su cultura artística e histórica. No podemos olvidar que estos viajes llamados culturales convirtieron a Venecia en la ciudad preferida de los poetas decadentes; a Florencia en el emblema de toda perfección, y a Roma en el grueso de la potencia creativa. Por todo esto, y sin pretensiones de agotar este tema, a continuación aludiremos a una de las primeras obras que narró el placer de viajar a Italia a partir de pequeños detalles, observaciones o reflexiones: Diario de viaje a Italia, por Suiza y Alemania (1774), de Michel de Montaigne (1533-1592), que, sin duda, es un claro antecedente del libro de Goethe.

Pues bien, hay que señalar que el creador del ensayo inició un viaje cultural por Italia a través de Suiza y Alemania el 22 de junio de 1580 que lo mantuvo alejado de su castillo y de su familia casi un año y medio (15 de noviembre de 1581), durante el cual visitó las ciudades de Venecia, Padua, Florencia o Roma. Ya se sabe que Montaigne, que sufría cólicos nefríticos que lo obligan a hacer estancias en aguas terapéuticas como las de Bagni della Villa, emprendió este recorrido -en compañía de su hermano pequeño,

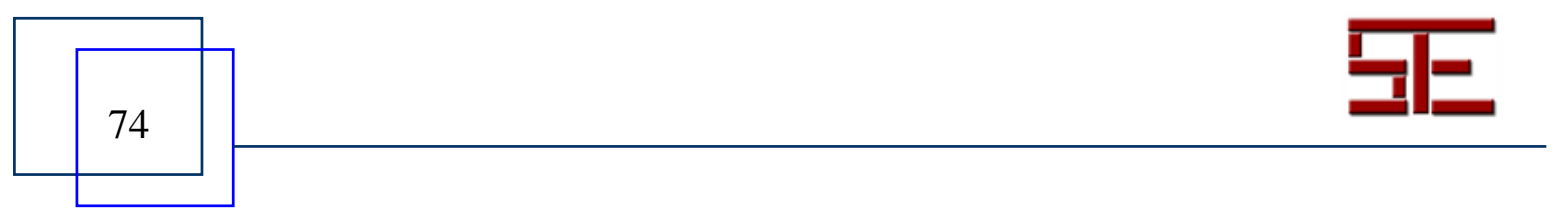




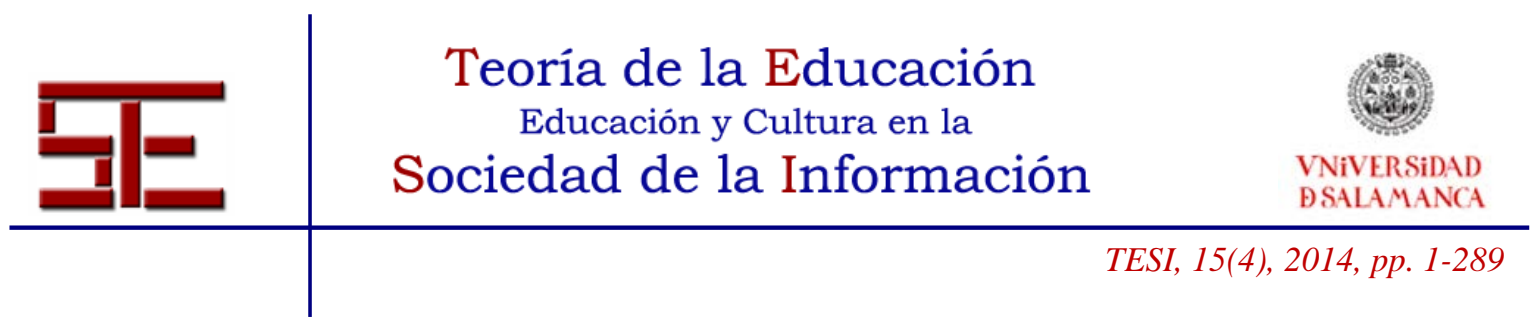

un pariente próximo, unos cuantos criados más una serie de caballos y burros con la carga necesaria- sin ninguna meta definida previamente ( pour se dépayser ), pero con la clara intención de huir del tedio derivado de la costumbre y de la cotidianidad.

Vista esta tradición cultural, no creemos que esté fuera de lugar afirmar que Italia y, por supuesto, su capital estaban en el punto de mira de toda la Europa más ilustrada desde el siglo XVI hasta el siglo XVIII a raíz de la cantidad de obras de arte que existe en esta península. Más adelante la situación cambió a favor de la ciudad de París puesto que, como es ampliamente conocido, se convirtió entonces en la capital cultural por excelencia y el marco idóneo para una gran cantidad de historias, fantasías y dramas.

Por otro lado, es el turno del viaje cultural como práctica heteroeducativa que será explicado a partir de un ejemplo mucho más cercano para nosotros dado que forma parte de la historia de la educación española. Nos estamos refiriendo al crucero por el Mediterráneo, integrado por 187 pasajeros a bordo que pertenecían a una élite intelectual y política (36 profesores y el resto eran estudiantes con un currículum académico brillante), que salió del puerto de Barcelona el 15 de junio de 1933 y llegó de regreso a Valencia el 1 de agosto de aquel mismo año.

Este viaje, que estuvo organizado por la Facultad de Filosofía y Letras de Madrid siguiendo los consejos de Fernando de los Ríos para llevar a cabo auténticas clases vivas de arte, de historia y de filosofía, hizo el siguiente itinerario: Túnez, Malta, Egipto, Palestina, Turquía, Creta, Rodas, Grecia, Sicilia, Italia y Mallorca.

Afortunadamente, la organización de este viaje de estudios promovió, con el propósito de organizar un concurso literario, que los estudiantes elaboraran un diario en el cual explicaran sus vivencias a bordo del barco (caminar a través del agua) o paseando por ciudades como El Cairo, Jerusalén, Atenas, Palermo o Nápoles. Fue ganado por Carlos Alonso de Real, Julián Marías y Antonio Muñoz Granell, cuyas impresiones fueron editadas, en 1934, en un libro titulado Juventud en el mundo antiguo. Es precisamente en esta obra donde hallamos estas palabras tan clarividentes:

Yo iba con el ánimo presto a ver cosas. Pero no ha sido sólo ver. Mucho más hondo ha entrado en mí. Hoy forma parte de mi ser más íntimo la emoción del desierto o el sentimiento religioso de la Via Crucis Hierosolimitana, igual que lo pueden formar mi gusto por Virgilio o mi mayor o menor afición al cinematógrafo. (...) Yo fui andar y a ver. Anduve y vi. (...) el que viene hoy a vosotros, trayendo su voz cargada de inflexiones de emoción y su ánimo entrenado en la captura de las cosas, no es exactamente el que se fue. Rico en emociones y en recuerdos. En trato con hombres y cosas. En satisfacción de haber realizado algo plenamente. (...) Vuelve más rico, más culto y cree que tal vez mejor en muchos sentidos (del Real, Marías y Granell, 1934, 188-189).

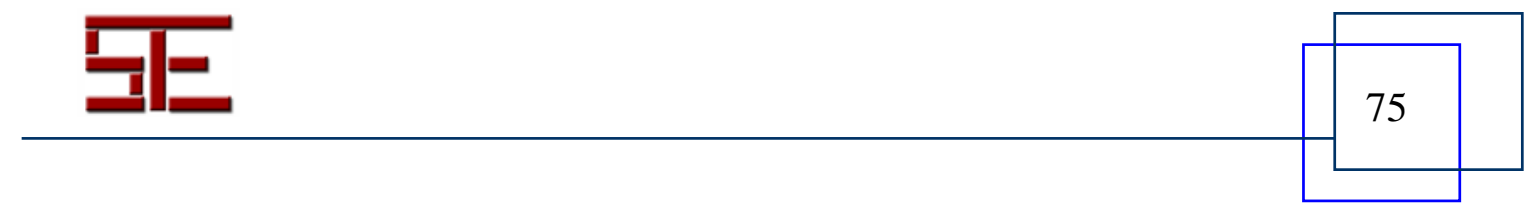




\section{Teoria de la Educación \\ Educación y Cultura en la \\ VNiVERSiDAD \\ DSALAMANCA \\ TESI, 15(4), 2014, pp. 1-289}

\section{4.- Caminatas autoformativas y reveladoras que nos guían hacia una opción postestructuralista}

Para empezar, hay que decir que somos plenamente conscientes de que Nietzsche se mostró especialmente crítico con el autoritarismo y el espíritu nacionalista del sistema educativo del Segundo Imperio (1871) y que el paradigma por excelencia de su concepción educativa es, como es ampliamente conocido, una sugerente frase del poeta griego Píndaro que subtitula su obra autobiográfica. Es decir: "llegar a ser lo que se es” (Píndaro, 1984, 152).

De forma epidérmica, diremos que nos plantea una educación en la que ya no es posible un modelo unitario de formación ni un ideal que sirva como patrón y, de este modo, los sujetos, que no son seres cerrados ni completos, siempre están inmersos en un camino que les lleva a ser aquello que está por crear. Por lo tanto, es obvio que la intención última de este dictum y, como consecuencia también esta forma de caminar que estamos abordando, es la voluntad de posibilitar un gran cambio y convertirse en algo nuevo a partir de la autosuperación humana, el dinamismo creativo y la autoformación.

Dicho esto, valga señalar que el pensamiento de este solitario de Sils-María influenció a importantes autores (Brandes, Heidegger y otros) desde los primeros compases del siglo pasado, a pesar de que su obra supuso un escándalo para los demócratas y un disparate mayúsculo para los catedráticos de filosofía en general.

Sin embargo, la verdadera rehabilitación de la filosofía nietzscheana sucedió después de los acontecimientos de Mayo del 68, puesto que se aprovechó aquel momento histórico proclive a las libertades individuales para criticar el totalitarismo de las filosofías de la historia. La cuestión es que Gilles Deuleze escribió Nietzsche y la filosofía y, Michel Foucault, un curso en el Collège de France durante el invierno de 1976 y la obra Nietzsche, la genealogía y la historia. Como es sabido, tuvo muy buena acogida, por lo cual nuevamente se consolidó el método histórico-genealógico, que evidencia las relaciones entre el saber y el poder que tienen lugar en el marco de las instituciones educativas. Más tarde, fue el turno de la deconstrucción derridana.

De este modo, podemos decir que surgió un movimiento que hoy en día es considerado una de las tradiciones pedagógicas que forman parte de la historia de la educación. Como es lógico, estamos hablando de la pedagogía postestructuralista, la cual supo aglutinar tanto las aportaciones de los autores que hemos comentado anteriormente como las del estructuralismo (Lévi-Strauss, Althusser, etc.). Se trata, pues, de una pedagogía que cuestiona abiertamente la institucionalización educativa (poder disciplinario y control social), dado que su finalidad es promover la autonomía individual para salvaguardar su independencia y gobernabilidad.

Una vez hecha la explicación sobre la recepción educativa de las ideas de Nietzsche, es oportuno realizar ahora una lectura pedagógica sobre el momento en que esta figura

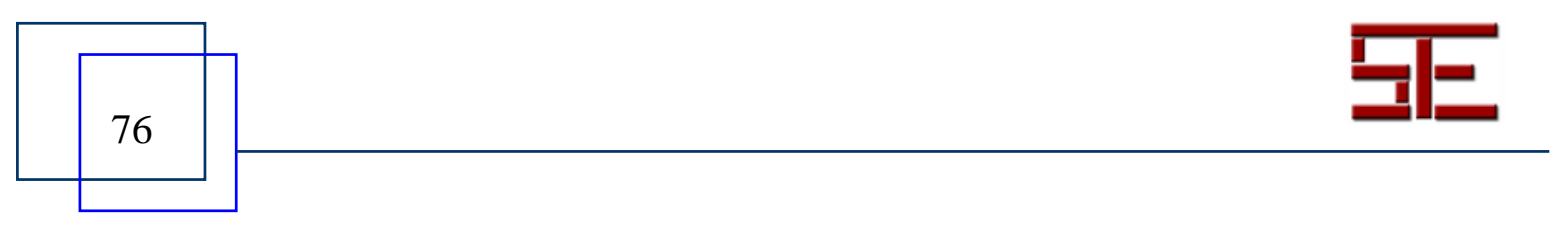




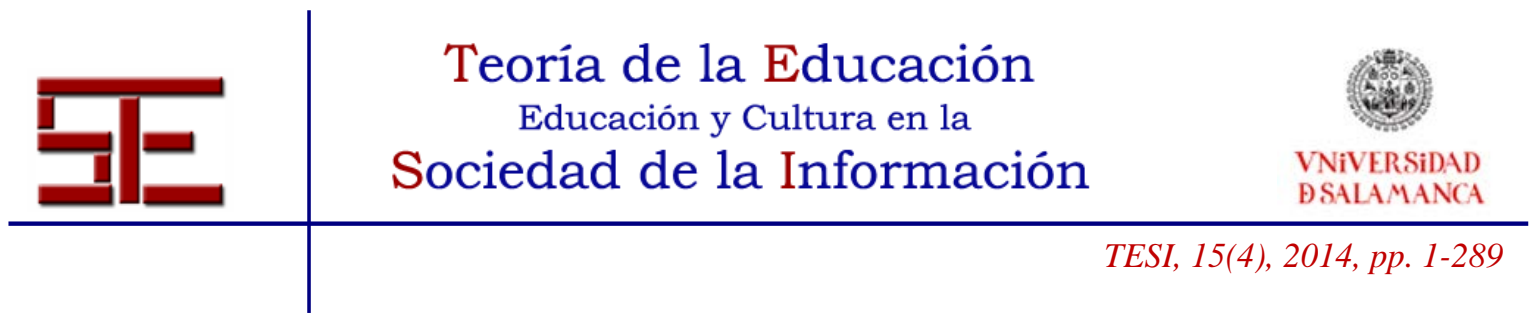

encontró sus ideas en lugares recónditos de la costa genovesa o de Sils-Maria, mediante dos apuntes breves.

Dado que sus caminatas tenían el propósito de llevar a cabo una verdadera transvaloración (recuperar el sentido de la vida como creación) que exige un cierto esfuerzo personal y una serie de desaprendizajes, sostenemos que el ejemplo de nuestro autor significa, tal y como anuncia en la obra Sobre el porvenir de nuestras escuelas (1872), una invitación a volver a aprender a caminar de otra forma (Nietzsche, 2000). En otras palabras: camina fuera de los paraguas de la tradición socrática y platónica, del cristianismo, el racionalismo o el utilitarismo.

Otro aspecto capital que podemos destacar es la emancipación individual o la incitación a regresar a la infancia, la cual no es otra cosa que reconducir nuestras prácticas hacia un camino más espontáneo y creativo. Sin embargo, y tal y como se proclama en Zaratustra, cabe decir que son necesarias tres transformaciones: en un primer momento, el espíritu se convierte en camello; más tarde, en león y, finalmente, en un niño. Que quede bien entendido: "Inocencia es el niño, y olvido, un nuevo comienzo, un juego, una rueda que se mueve por sí misma, un primer movimiento, un santo decir sí. Sí, hermanos míos, para el juego del crear se precisa un santo decir sí: el espíritu quiere ahora su voluntad, el retirado del mundo conquista ahora su mundo” (Nietzsche, 2008, 55). Y, con relación a nuestro asunto, comentamos que sería una forma de estar-enmovimiento desorganizada, sin ritmo ni equilibrio pero siempre dando entrada a todas las novedades imprevistas.

\section{A MODO DE CONCLUSIONES}

Situados en esta última fase, coronamos nuestro recorrido exponiendo aquellas consideraciones fundamentales defendidas líneas más arriba en forma de tres apuntes breves con la intención de abrir un debate acerca de la relación entre la pedagogía y el acto de caminar. Sostenemos asimismo que las aportaciones de este artículo, junto con otros trabajos ya publicados ${ }^{9}$, pueden dar pie a otros estudios o investigaciones parecidos en el campo de los estudios filosófico-educativos.

\section{1.- Caminar garantiza la continuidad del Homo viātor en nuestro interior}

Dado que en nuestro contexto parece que exista una dinámica neosedentaria muy extensa, pensamos que este texto puede ser una empresa muy oportuna por dos motivos. Por un lado, distinguimos una cuestión más bien histórica: el deseo de dar continuidad a

\footnotetext{
${ }^{9}$ Básicamente nos estamos refiriendo a dos obras: Maaschelein, J. (2006). Pongámonos en marcha. En Maaschelein, J. y Simons, M. (eds.) Mensajes e-ducativos desde tierra de nadie (21-30). Barcelona: Laertes y Úcar, X. (1998). Virtudes pedagógicas del Camino de Santiago. En Pantoja, L. (ed.) Nuevos espacios de la educación social (407-410). Bilbao: Universidad de Deusto.
}

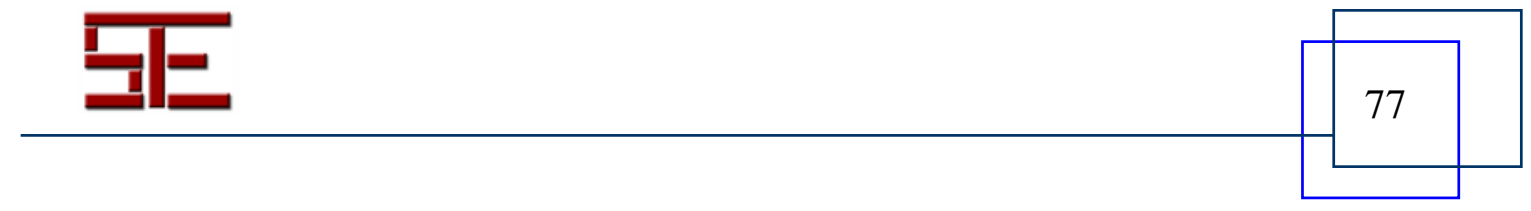




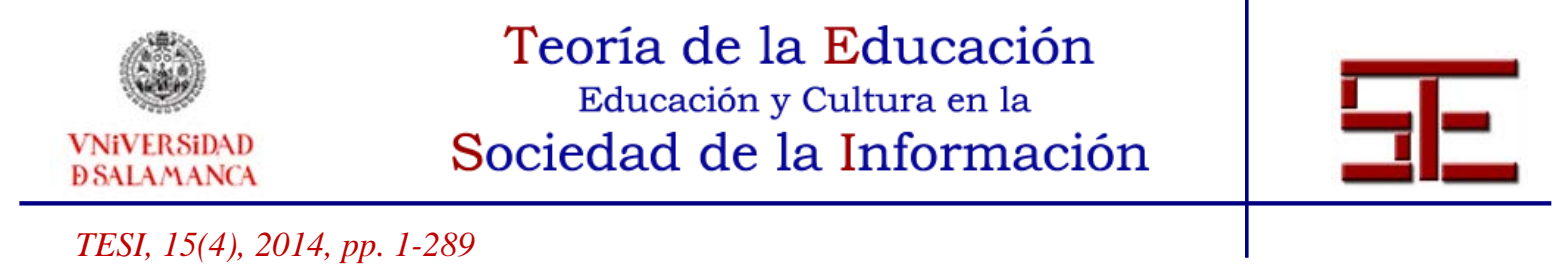

nuestra larga tradición pedestre con todas sus variantes posibles (el peregrino, el excursionista, el exiliado, el fugitivo, el viajero, el turista, el escritor de viajes o el vagabundo) en nuestro continente ${ }^{10}$. En otras palabras: es una invitación a ponernos en marcha, a llenar de sentido los trayectos y a disfrutar de una vida a la intemperie. Y, por otro, la voluntad irrenunciable de mantener esta dimensión porque nos humaniza proporcionándonos tiempo y, además, vuelve más habitable este mundo ante unos valores que cada vez priorizan más lo que transmite el espíritu automovilístico y tecnológico (inmediatez, velocidad, superficialidad o ligereza).

Como consecuencia de esto, lo que pretendemos señalar es que no se puede negar que caminar nos brinda la oportunidad de convertirnos en un Homo viātor, es decir, en un individuo-que-está-en-movimiento sin la pretensión de llegar lo antes posible a su destino porque quiere disfrutar de un ritmo más apropiado que le permita una sensación de aliento vital y, por supuesto, pensar, ya que convierte su itinerario en un tipo de biblioteca, taller o laboratorio para disfrutar una verdadera aventura intelectual. No obstante, también merece la pena recordar que, a pesar de sus evidentes virtudes y de que estamos inmersos en un mundo de liebres, no es conveniente hacer caminar a quienes no quieren hacerlo porque sería una tortura muy absurda. Esta estrategia solamente nos llevaría a un lugar nada deseable: más incomprensión por la delicia de pasear.

\section{2.- Caminar facilita pensar la educación desde varias cosmovisiones pedagógicas}

Volviendo a confirmar que la relación entre la pedagogía y el acto de caminar se fundamenta en una antropología que presenta al ser humano como un Homo viātor que se encuentra siempre en camino (in itinere), es notorio que la tesis más importante de este artículo es que este movimiento es una situación totalmente idónea para que un sujeto viva un proceso formativo pudiendo desarrollar sus capacidades intelectuales, morales o estéticas. Dicho de otro modo: caminar es una forma de hacer camino y de (auto)formarse o (hetero)educarse.

Dicho esto, pasamos a mencionar los dos caminos que aparecen actualmente cuando pensamos la educación desde el hecho de ir a pie. Existe, por un lado, una primera concepción, cada vez más dominante, en que la educación se convierte en una ciencia aplicada y, por este motivo, las caminatas educativas se convierten en una puesta en

\footnotetext{
${ }^{10}$ En este sentido, ahora es oportuno recordar estas palabras de Steiner tan claras: "Europa ha sido y es paseada. Esto es fundamental. La cartografía de Europa tiene su origen en las capacidades de los pies humanos, en lo que se considera son sus horizontes. Los hombres y mujeres europeos han caminado por sus mapas, de aldea en aldea, de pueblo en pueblo, de ciudad en ciudad. La mayoría de las veces, las distancias poseen una escala humana, pueden ser dominadas por el viajero a pie, por el peregrino a Compostela, por el promeneur, ya sea solitario, ya gregario. Hay trechos de terreno árido, intimidatorio; hay ciénagas, se elevan altas cumbres. Pero ninguna de estas cosas constituye un obstáculo definitivo" (Steiner, 2008, 40).
}

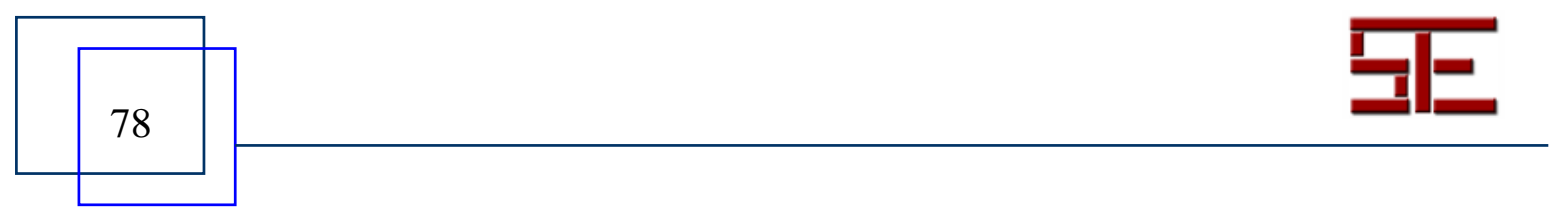




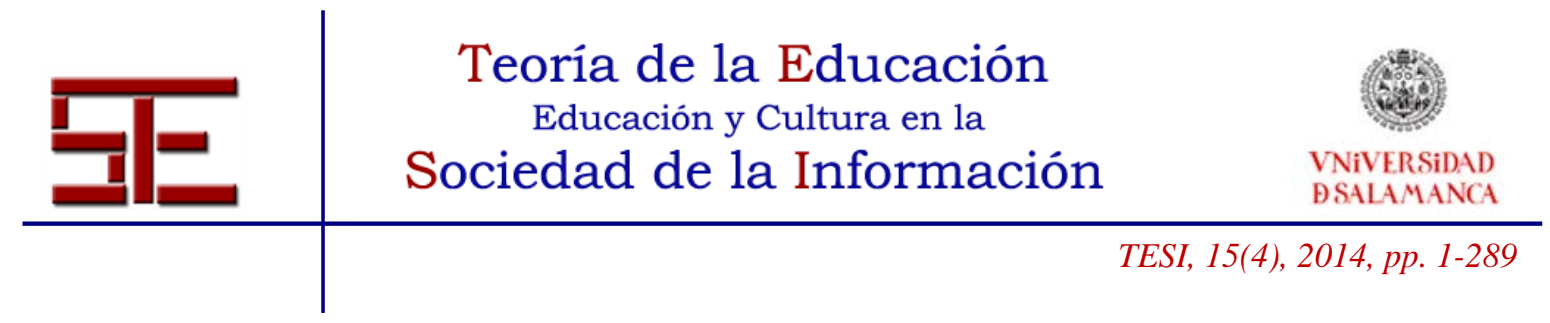

práctica -con más o menos eficacia- de varias tecnologías pedagógicas diseñadas por científicos o tecnólogos (Homo viātor $\tau \varepsilon \chi v o \lambda o \gamma ı \kappa o ́ \varsigma)$. De esto tenemos pruebas: la aplicación llamada Mobile history maps o la QuesTInSitu ${ }^{11}$, de tipo e-learning y que utiliza Google Maps para apoyar la creación de rutas educativas interactivas para actividades de test in situ.

$\mathrm{Y}$, por otro lado, se constata todas aquellas cosmovisiones pedagógicas que, pese a sus grandes diferencias, nos han servido para configurar nuestro modelo educativo. La primera de ellas es aquella que entiende la naturaleza como el medio más idóneo para cualquier proceso de enseñanza-aprendizaje, dado que considera que escuchar su voz es garantía de escoger el camino certero y verdadero. En este sentido, esta forma de caminar también supone respetar el orden natural. También, destacamos la educación entendida como un proceso de vivificación cultural y espiritual que intenta incluir, agrupar e integrar todas las tradiciones en la cultura. Como es muy lógico, en esta ocasión es el modelo de la Bildung, que incorpora una serie de ideales formativos de la tradición humanista a la forma de transitar. Y, en último término, es el turno de la educación que cuestiona la obligatoriedad de asistencia a la escuela planteando diferentes alternativas de talante más informal y antiinstitucional.

Así pues, no es en balde decir que los caminares educativo defendidos por este texto se inscriben en las tres últimas opciones porque plantean una pedagogía concebida como una experiencia de significados y de sentido en lugar de una que está estrechamente relacionada con los modelos técnicos instrumentales, la cual reduce cualquier proceso educativo a una simple estrategia que busca el éxito y la eficacia. En definitiva: tanto las prácticas educativas organizadas y guiadas por instituciones educativas y culturales como experiencias totalmente autoformativas y errantes, siempre nacen de nuestras vivencias y de una experiencia pedestre bien significativa.

\section{3.- El caminar bien entendido tiene muchas posibilidades en el campo educativo siempre que sepamos darle un uso preciso}

A la vista de lo que acabamos de decir, concluiremos conjeturando que el modelo educativo establecido en el apartado anterior a partir del neonomadismo pedagógico en calidad de eje vertebrador junto con conocidas prácticas autoformativas y heteroeducativas es, sin duda, una de las líneas de investigación que puede tener mayor prospección en el campo educativo por sus enormes posibilidades. Brevemente volvemos a destacar alguna: tiene la voluntad de establecer una relación educativa con uno mismo (calma, silencio, satisfacer las necesidades más profundas); posibilita que los aprendizajes y los pensamientos nunca dejen de fluir sin ningún tipo de dogmatismo;

\footnotetext{
11 Merece la pena mencionar que esta aplicación ha sido desarrollada por el equipo de Tecnologías educativas del Grupo de Investigación en Tecnologías Interactivas (GTI) de la Universitat Pompeu Fabra. Más información: <http://gti.upf.edu/questinsitu/> [fecha de consulta: 23/01/2014].
}

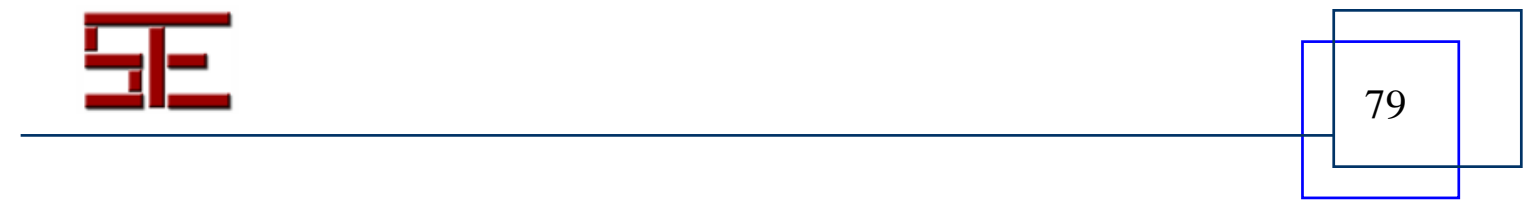




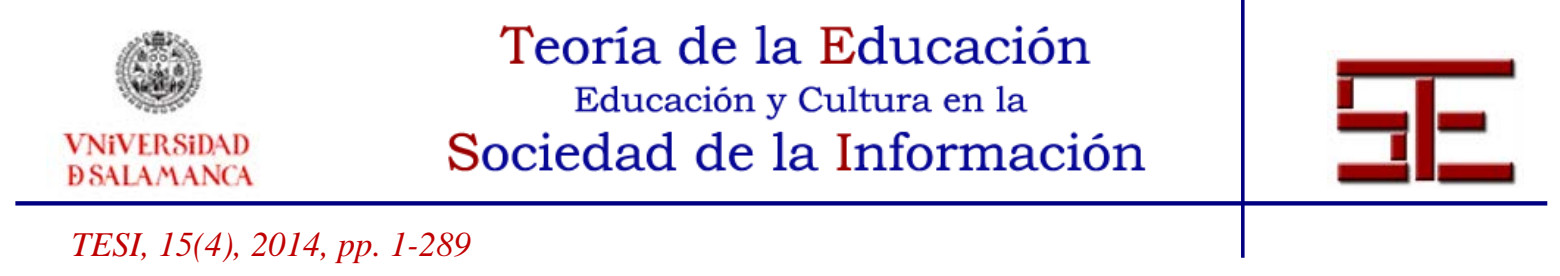

permite vivir más satisfactoriamente; enseña cosas importantes $\mathrm{y}$, en último término, suele convertir a sus caminantes en mejores ciudadanos y personas.

Sea como fuere, existe otra prueba que también puede confirmar la previsión que acabamos de reseñar: la detección de diferentes iniciativas docentes que han sabido conjugar la educación y el caminar como metodología formativa recientemente y, por consiguiente, rompe con dicotomías tan conocidas como teoría/práctica, vida/escuela, pensamiento/acción. A modo de ejemplo, destacamos tres actuales que provienen de distintas disciplinas (filosofía, pedagogía y urbanismo).

Primeramente, citamos el peregrinaje filosófico del gran pensador Raimon Pannikar a la montaña sagrada Kailasa junto a una de sus discípulas, Milena Carrara. Creemos que su libro Peregrinación al Kailasa y al centro de sí es un buen testimonio para entender las transformaciones que puede sufrir un peregrino en este tipo de itinerarios y, además, la maestría que genera cuando se camina junto a un autor de esta magnitud. Luego, subrayamos la pedagogía de la reiteración propuesta por el profesor Xavier Laudo que, en el marco de asignaturas relacionadas con la historia de la educación del grado de pedagogía, consiste en conducir al educando a vivir un acontecimiento del pasado a través del acto de volver a hacer in situ un itinerario significativo ${ }^{12}$. Por último, queremos destacar la asignatura Caminar Barcelona -impartida en la UPC por el profesor Estanislau Roca- puesto que aborda los temas de la arquitectura y del urbanismo mediante recorridos por diferentes áreas de la ciudad ${ }^{13}$.

\section{REFERENCIAS}

Alonso, C. (1934). Juventud en el mundo antiguo: crucero universitario por el mediterráneo. Madrid: Espasa-Calpe.

Baden-Powell, R. (1976). Escultismo para muchachos. Barcelona: Oidà.

Benjamin, W. (2005). Dirección única. Madrid: Alfaguara.

Bollnow, O. F. (1969). Hombre y espacio. Barcelona: Editorial Labor SA.

\footnotetext{
${ }^{12}$ Véase LAUDO, X.; ANSÓ, M. (2009). La pedagogía de la reiteración en la docencia en Historia de la Educación. La experiencia “¿Quién mató a Walter Benjamin?”, en REYES, M.; CONEJERO, S. (Coords.) El largo camino hacia una educación inclusiva: la educación especial y social del siglo XIX a nuestros días. XV Coloquio de Historia de la Educación Vol. II. Pamplona-Iruñea: Universidad Pública de Navarra, 727-736.

${ }^{13}$ ROCA, E. (2011) Caminar Barcelona. 14è Premi UPC a la Qualitat en la Docència Universitària. Barcelona: Universitat Politècnica de Catalunya.
}

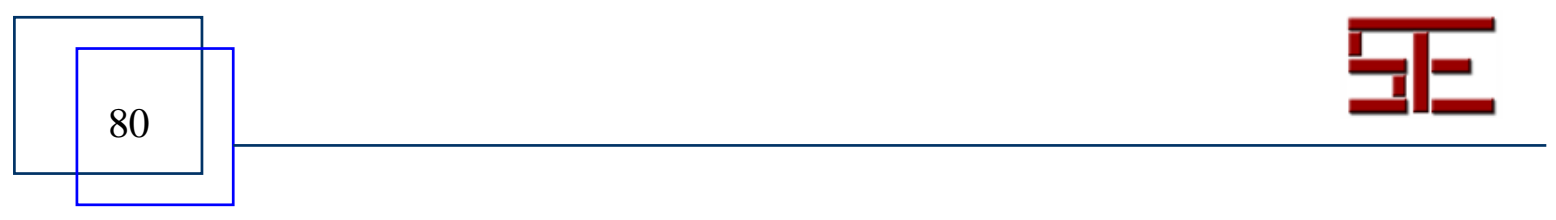




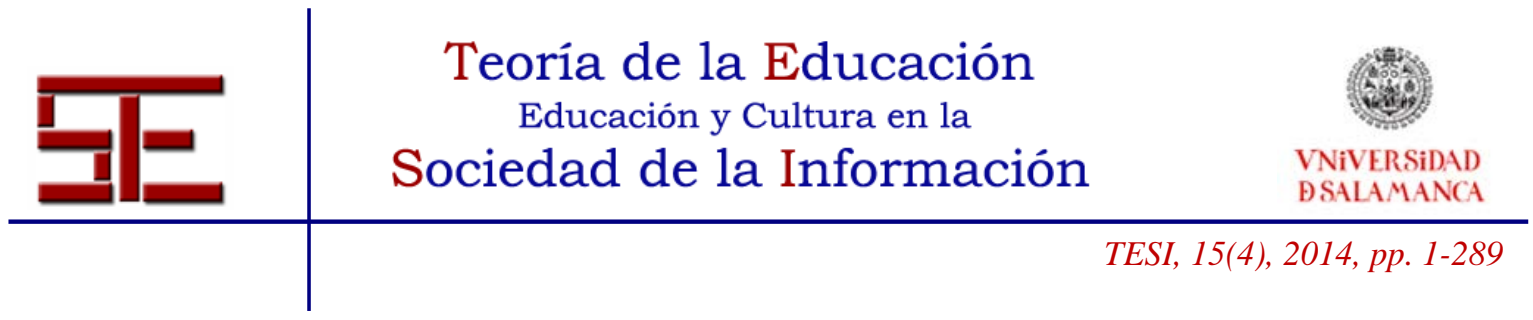

Careri, F. (2002). Walkscapes. El andar como práctica estética. Barcelona: Gustavo Gili.

Coromines, J. (1980). Diccionario crítico etimológico castellano e hispánico. Vol. I. Madrid: Editorial Gredos SA.

Del Real, C.; Marías, J. y Granell, M. (1934). Juventud en el mundo antiguo (crucero universitario por el mediterráneo). Madrid: Talleres Espasa-Calpe SA.

Deleuze, G. (1971). Nietzsche y la filosofía. Barcelona: Anagrama.

Delgado, M. (2007). Sociedades movedizas. Pasos hacia una antropología de las calles. Barcelona: Anagrama.

Demetrio, D. (2005). Filosofia del camminare. Esercizi di meditazione mediterranea. Milano: Raffaello Cortina Editore.

Dilthey, W. (1994). Teoría de las concepciones del mundo. Barcelona: Ediciones Altaya SA.

Eckermann, J. P. (2000). Conversaciones con Goethe. México DF: CONACULTA y Océano.

Ferrer Guàrdia, F. (2010). La escuela moderna. Madrid: Biblioteca Nueva.

Foucault, M. (1988). Nietzsche, la genealogía, la historia. Valencia: Pre-textos.

Freinet, C. (1976). Técnicas Freinet de la escuela moderna. México DF: Siglo veintiuno editores SA.

Fröbel, F. (1913). La educación del hombre. Madrid: Daniel Jorro.

Gadamer, H.-G. (2012). Verdad y método. Salamanca: Ediciones Sígueme.

Goethe, J. W. von (1994). La metamorfosis de las plantas. Bilbao: Beitia ediciones.

— (1999): Poesía y verdad. Barcelona: Alba Editorial SL.

— (2000): Los Años de aprendizaje de Wilhelm Meister. Madrid: Cátedra.

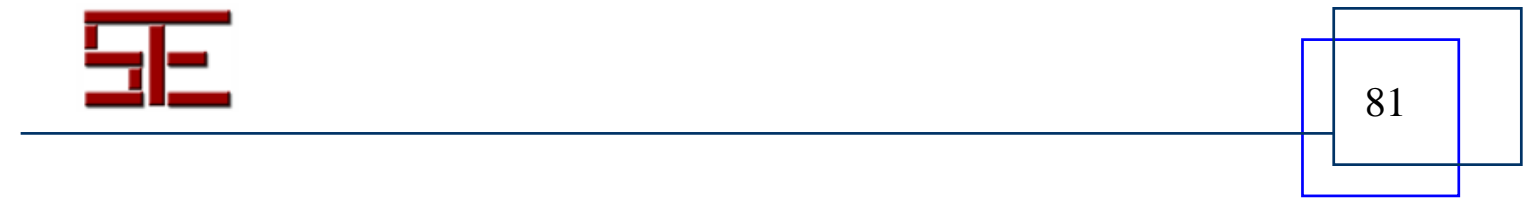




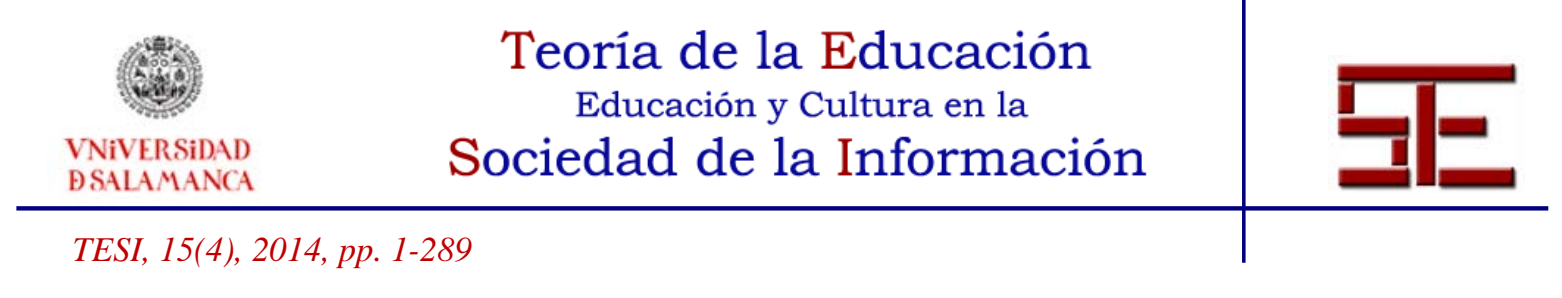

— (2009): Viaje a Italia. Barcelona: Edicones B.

Gros, F. (2009). Marcher, une philosophie. Paris: Carnets Nord.

Hazlitt, W. y Stevenson, R. L. (2003). El arte de caminar. México DF: UNAM.

Heidegger, M. (2003). Ser y tiempo. Madrid: Trotta.

Janz, C. P. (1978). Friedrich Nietzsche. Los diez años del filósofo errante (1879-1889).

Madrid: Alianza Editorial.

Jaspers, K. (1967). Psicología de las concepciones del mundo. Madrid: Editorial Gredos SA.

Laudo, X.; Ansó, M. (2009). La pedagogía de la reiteración en la docencia en Historia de la Educación. La experiencia “¿Quién mató a Walter Benjamin?”. En REYES, M.; CONEJERO, S. (Coords.) El largo camino hacia una educación inclusiva: la educación especial y social del siglo XIX a nuestros días. XV Coloquio de Historia de la Educación Vol. II (pp. 727-736). Pamplona-Iruñea: Universidad Pública de Navarra.

- (2013). Història cultural, historia postsocial, pedagogia de la reiteració: entre la recerca de la veritat i el manteniment de la conversa. Temps d'Educació, 44, 13-32.

Le Breton, David (2000). Eloge de la marche. París: Éditions Métailié.

Linné, C. von (1788). Sistema de los vegetables. Madrid: Imprenta Real.

Maaschelein, J. (2006). Pongámonos en marcha. En MAASCHELEIN, J. y SIMONS, M. (eds.) Mensajes e-ducativos desde tierra de nadie (pp. 21-30). Barcelona: Laertes.

Marcel, G. (2005). Homo viator. Prolegómenos a una metafísica de la esperanza. Salamanca: Ediciones Sígueme.

Montaigne, M. de (1986). Diario de viaje a Italia, por Suiza y Alemania. Barcelona: Edicions 62.

Nietzsche, F. (1971). Ecce homo: cómo se llega a ser lo que se es. Madrid: Alianza Editorial SA.

— (2000). Sobre el porvenir de nuestras escuelas Barcelona: Tusquets.

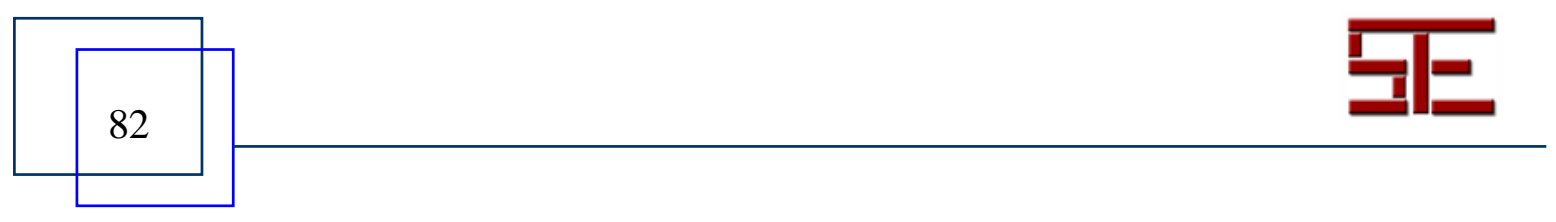




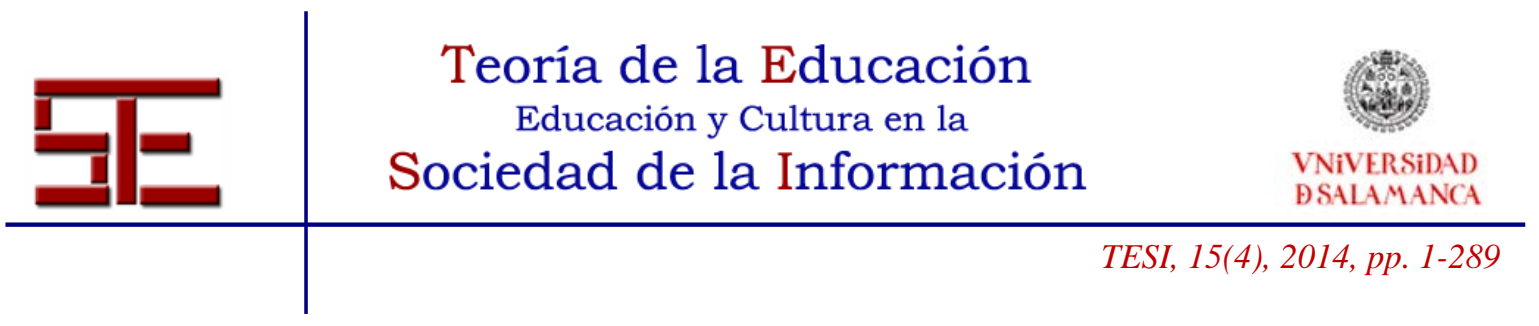

— (2008). Así habló Zaratustra. Madrid: Alianza.

— (2009). La Gaya ciencia. Madrid: Ediciones Akal SA

Panikkar, R.; Carrara, M. (2009). Peregrinación al Kailasa y al centro de sí. Barcelona: Ediciones Luciérnaga.

Pieper, J. (1980). Las virtudes fundamentales. Madrid: Ediciones Rialp SA.

Píndaro (1984). Odas y fragmentos. Madrid: Editorial Gredos SA.

Real Academia Española (2001). Diccionario de la lengua española (22. a ed.). Madrid: Autor.

Roca, E. (2011). Caminar Barcelona. 14è Premi UPC a la Qualitat en la Docència Universitària. Barcelona: Universitat Politècnica de Catalunya.

Rousseau, J.-J. (2003). Emilio, o De la educación. Madrid: Alianza.

— (2007a). Las confesiones. Madrid: Alianza Editorial SA.

— (2007b). Cartas sobre botánica. Oviedo: KRK ediciones.

— (2008). Las ensoñaciones del paseante solitario. Madrid: Alianza Editorial SA.

Söetard, M. (1995). Jean-Jacques Rousseau (1712-1778). En HOUSSAYE, J. (ed.) Quinze pedagogs. La seva influència, avui (pp. 31-44). Barcelona: Edicions Proa SA y Universitat Oberta de Catalunya.

Spranger, E. (1961). Formas de vida. Psicología y ética de la personalidad. Madrid: Revista de Occidente.

Steiner, G. (2008). La idea de Europa. Madrid: Ediciones Siruela.

Todorov, T. (1987). Frágil felicidad. Un ensayo sobre Rousseau. Barcelona: Gedisa.

Tolstoi, L. (1978). La escuela de Yasnaia Poliana. Barcelona: Pequeña Biblioteca Calamus Scriptorius.

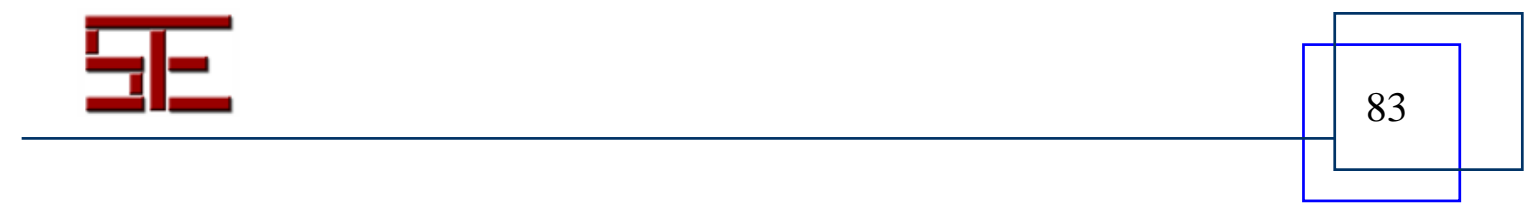


Tusquets, J. (1981-1982). El nomadisme pedagògic a Catalunya. Boletín de la Real Academia de Buenas Letras, 38, 207-223.

- (1983-84). El sedentarisme pedagògic a Catalunya. Boletín de la Real Academia de Buenas Letras, 39, 83-92.

- (1986): Tarzán contra robot. El neonomadismo y el neosedentarismo protagonistas de la crisis contemporánea. Barcelona: Oikos-tau SA.

Úcar, X. (1998). Virtudes pedagógicas del Camino de Santiago. En PANTOJA, L. (ed.) Nuevos espacios de la educación social (pp. 407-410). Bilbao: Universidad de Deusto.

Vilanou, C. (2001). De la ‘Bildung’ a la Pedagogía Hermenéutica. Ars Brevis, 7, 255279.

Winckelmann, J. J. (2011). Historia del Arte de la Antigüedad. Madrid: Akal.

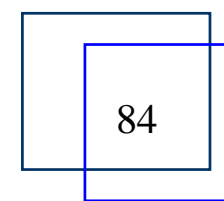

